\title{
Fingerprinting of neurotoxic compounds using a mouse embryonic stem cell dual luminescence reporter assay
}

\author{
Marilena Colaianna $^{1} \cdot$ Sten Ilmjärv $^{1} \cdot$ Hedi Peterson $^{2} \cdot$ Ilse Kern $^{3,4}$. \\ Stephanie Julien ${ }^{1}$ Mathurin Baquié ${ }^{5} \cdot$ Giorgia Pallocca $^{6} \cdot$ Sieto Bosgra $^{7,10}$ • \\ Agapios Sachinidis $^{8} \cdot$ Jan G. Hengstler $^{9} \cdot$ Marcel Leist $^{6} \cdot$ Karl-Heinz Krause $^{1,4}$
}

Received: 9 October 2015 / Accepted: 10 March 2016 / Published online: 25 March 2016

(C) The Author(s) 2016. This article is published with open access at Springerlink.com

\begin{abstract}
Identification of neurotoxic drugs and environmental chemicals is an important challenge. However, only few tools to address this topic are available. The aim of this study was to develop a neurotoxicity/developmental neurotoxicity (DNT) test system, using the pluripotent mouse embryonic stem cell line CGR8 (ESCs). The test system uses ESCs at two differentiation stages: undifferentiated ESCs and ESC-derived neurons. Under each condition, concentration-response curves were obtained for three parameters: activity of the tubulin alpha 1 promoter (typically activated in early neurons), activity of the elongation factor 1 alpha promoter (active in all cells), and total DNA content (proportional to the number of surviving cells). We tested 37 compounds from the ESNATS test battery, which includes polypeptide hormones, environmental pollutants (including methylmercury), and clinically used drugs (including valproic acid and tyrosine kinase inhibitors). Different classes
\end{abstract}

Electronic supplementary material The online version of this article (doi:10.1007/s00204-016-1690-2) contains supplementary material, which is available to authorized users.

Karl-Heinz Krause

Karl-Heinz.Krause@unige.ch

1 Department of Pathology and Immunology, Medical School, University of Geneva, Geneva, Switzerland

2 Quretec Ltd, Ülikooli 6a, Tartu, Estonia

3 Department of Pediatrics, Geneva University Hospital, Geneva, Switzerland

4 Department of Genetic and Laboratory Medicine, Geneva University Hospital, Centre Medical Universitaire, Rue Michel-Servet, 1211 Geneva 4, Switzerland

5 NEURIX SA, Geneva, Switzerland of compounds showed distinct concentration-response profiles. Plotting of the lowest observed adverse effect concentrations (LOAEL) of the neuronal promoter activity against the general promoter activity or against cytotoxicity, allowed the differentiation between neurotoxic/ DNT substances and non-neurotoxic controls. Reporter activity responses in neurons were more susceptible to neurotoxic compounds than the reporter activities in ESCs from which they were derived. To relate the effective/toxic concentrations found in our study to relevant in vivo concentrations, we used a reverse pharmacokinetic modeling approach for three exemplary compounds (teriflunomide, geldanamycin, abiraterone). The dual luminescence reporter assay described in this study allows high-throughput, and should be particularly useful for the prioritization of the neurotoxic potential of a large number of compounds.

Keywords Mouse embryonic stem cells . Neuroactivity · Neurotoxicity · In vitro screening · Neuronal differentiation

6 Doerenkamp-Zbinden Chair for In Vitro Toxicology and Biomedicine, University of Konstanz, Constance, Germany

7 TNO, Zeist, The Netherlands

8 Institute of Neurophysiology and Center for Molecular Medicine Cologne (CMMC), University of Cologne, Cologne, Germany

9 Leibniz Research Centre for Working Environment and Human Factors (IfADo), Technical University of Dortmund, Dortmund, Germany

10 Present Address: BioMarin Pharmaceutical Inc., Leiden, The Netherlands 


\section{Introduction}

Identification of neurotoxicity or developmental neurotoxicity is an important challenge. Animal tests remain the principal experimental approach. Although the guidelines for testing neurodevelopmental toxicity of compounds (Tsuji and Crofton 2012) rely mainly on in vivo testing, logistic, scientific, and ethical arguments suggest that wellcontrolled in vitro systems that detect neurodevelopmental toxicity and/or neurotoxicity should be developed (Hartung and Leist 2008; Leist et al. 2008). Stem cell-based technologies are particularly promising in this respect and the EU consortium "embryonic stem cell-based novel alternative tests" (ESNATS www.esnats.eu) was dedicated to the development of such in vitro systems. Several toxicity test systems were developed in the context of this consortium (Leist et al. 2013), including transcriptomics-based assays (Krug et al. 2013b; Zimmer et al. 2011), a neurite extension assay (Krug et al. 2013a), and a neural crest migration assay (Zimmer et al. 2012, 2014). Given the different parameters measured by different neurotoxicity assays, it is likely that the combination of different in vitro tests, i.e., a test battery will be the most promising approach for predictive in vitro testing (Leist et al. 2014; Zimmer et al. 2014).

Generally, two types of neurotoxicity are distinguished: developmental neurotoxicity (DNT), which basically refers to the impact of toxicants on the highly sensitive developing brain, and general neurotoxicity which occurs in the mature brain and peripheral nervous system (Bal-Price et al. 2015; Smirnova et al. 2014). In many cases, compounds, such as methylmercury, that cause developmental neurotoxicity at low exposure levels may also lead to general neurotoxicity at higher exposure levels. However, other compounds, such as valproic acid, that are clearly developmental neurotoxicants show little evidence for toxicity to the mature brain. Noteworthy, identification and classification of compounds in these categories based on currently available studies appear to be uneasy. Major limitations of presently available studies on neurotoxicity, both developmental and general, include the following aspects:

- Relatively few clinical and epidemiological data are available (Smirnova et al. 2014). Well-accepted exceptions are tragic events such as the large-scale methylmercury poisoning in Minamata (Ekino et al. 2007) or the identification of the fetal valproate syndrome because of the widespread treatment of pregnant epileptic patients with valproic acid (Ozkan et al. 2011; Smith and Whitehall 2009);

- Neurotoxicity is typically not characterized by cytotoxicity (i.e., neuronal cell death), but rather by impact of toxicants on connectivity, structure, and function of the nervous system during development or at maturity (Giordano and Costa 2012);

- Extrapolation of data from animal experiments to the human situation may be challenging due to interspecies differences ("humans are no $70 \mathrm{~kg}$ mice" (Leist and Hartung 2013);

- In vitro studies on neurotoxicity usually use transformed or cancer cell lines, which have a response pattern significantly different from normal cells (Kadereit et al. 2012; Stiegler et al. 2011).

Validated in vitro methods using stem cell-derived neurons and neural tissues might overcome several of the above cited limitations and allow a more reliable prediction of neurotoxicity (Coecke et al. 2007; Krug et al. 2013b; Pistollato et al. 2012; Rovida et al. 2011; van Thriel et al. 2012). Pluripotent stem cells provide attractive cellular systems for in vitro toxicology studies, because they are nontransformed cells and have the potential to differentiate into the main neural lineages such as neural progenitors cells, neurons, and glial cells (Breier et al. 2010; Kuegler et al. 2010) and provide the starting material for neural tissue engineering (Preynat-Seauve et al. 2009).

The validation of novel in vitro neurotoxicity test systems strongly depends on the availability of well-characterized neurotoxic as well as non-neurotoxic compounds. For this purpose, the ESNATS consortium has developed a compound collection, including the so-called test battery compounds (Zimmer et al. 2014) as well as organomercury compounds and HDAC inhibitors (Krug et al. 2013b). The test battery compound collection includes several classes of compounds, pharmaceuticals (e.g., abiraterone, amiodarone), biologics (e.g., interferon- $\beta$, oxytocin), peptide-related small molecules (e.g., sitagliptin, galnon), and environmental pollutants (e.g., PDBE-99, triadimefon). The most widely used model compounds for neurotoxicity are valproic acid and methylmercury. Valproic acid is mostly a developmental neurotoxicant, while methylmercury also causes general neurotoxicity in humans and animals (Kadereit et al. 2012; Wang et al. 2011). When given to pregnant women, the anti-epileptic drug valproic acid causes neural tube defects; in vitro, it triggers relevant changes of the cellular transcriptome through the inhibition of histone deacetylases (HDAC) (Krug et al. 2013b; Theunissen et al. 2011). The mechanisms of action of methylmercury still have not been completely elucidated, but its usefulness as a neurotoxic model compound is undisputed because of the abundantly available clinical data on human neurodevelopmental toxicity and general neurotoxicity (Clarkson and Strain 2003; Davidson et al. 2004; Ekino et al. 2007; Harada 1995). During developmental exposure, methylmercury causes among others 
neural tube defects (Grandjean and Herz 2011; Robinson et al. 2011), while in the adult exposed to the compound, symptoms such as blurred vision, hearing impairment, olfactory and gustatory disturbances, cerebellar ataxia, somatosensory, and psychiatric disorders were observed (Ekino et al. 2007).

The major limitation of many in vitro neurotoxicity assays is the fact that they are labor-intensive and timeconsuming. Mouse embryonic stem cell (mESC) systems show a higher throughput and robustness when compared to the human counterpart, and they offer a better chance to compare in vitro data with the already existing murine and rat in vivo databases (Kuegler et al. 2010; Leist et al. 2013). Furthermore, these systems can be easily engineered for high content imaging (HCI) approaches (van Vliet et al. 2014) or with reporter constructs providing a faster readout. We have previously developed a dual-luciferase reporter construct that upon expression in mouse embryonic stem cells provide read-out in stem cell-derived neurons (Suter et al. 2009). In the context of the ESNATS consortium, we have screened a 1000-compound library with a single fixed concentration per compound, demonstrating the potential of this assay (Kern et al. 2013).

In the present study, we used the dual luminescence reporter assay to establish a high-throughput neurotoxicity test that compares the impact of toxicants on undifferentiated pluripotent stem cells (ESCs) with the impact on differentiated ESC-derived neurons. For each tested compound, the assay determines six dose-response curves: three dose-response curves in undifferentiated ESCs, and three in ESC-derived neurons. To evaluate the human relevance of concentrations tested positive in the dual luminescence reporter assay, a physiology-based pharmacokinetic (PBPK) reverse modeling method was applied. We propose this approach as a promising tool for identifying compounds that may cause DNT/neurotoxicity.

\section{Materials and methods}

\section{Chemicals}

Murine CGR8 ESCs were purchased from European Collection of Cell Culture. The bone marrow stromal MS5 cell line was kindly provided by Katsuhiko Itoh (Itoh et al. 1989). Cell culture reagents were purchased from Gibco, Invitrogen Corporation (Paisley, Scotland). Dual-luciferase ${ }^{\circledR}$ Reporter Assay System was from Promega (Madison, WI, USA), the Fluostar Optima reader from BMG Labtech GmbH (Hanns-Martin-Schleyer-Str. 10, D-7656 Offenburg/Germany), and the Flexstation 3 microplate reader from Molecular Devices (Sunnyvale, California, USA). All non-neurotoxic and cytotoxic controls used in this study were obtained from Sigma. Providers of the other compounds are listed in Table 1.

\section{CGR8-2Luc cells}

Dual luciferase expressing CGR8-2Luc cells were obtained by transduction of mouse ESC CGR8 cells with the $2 \mathrm{~K} 7$ EFS-Renilla Luciferase (RLuc)/Talpha1-Firefly Luciferase (FLuc) vector as previously described (Suter et al. 2006, 2009); EFS corresponds to the short promoter of the eukaryotic translation elongation factor 1 alpha $(\mathrm{EF} 1 \alpha)$, and Talpha1 to the Tubulin $\alpha 1$ (T $\alpha 1)$ promoter. T $\alpha 1$ was selected as a promoter active in neurons, including early stages of neural differentiation. EF1 $\alpha$ was originally selected to function as a constitutive promoter; however, it responds to cellular differentiation as well as to various chemicals, as previously shown (Kern et al. 2013). Cells were cultured on $0.1 \%$ gelatin-coated dishes in CGR8-2luc maintenance medium: BHK21 medium, supplemented with $10 \%$ fetal calf serum, L-glutamine, non-essential amino acids, penicillin/streptomycin, and leukemia inhibitory factor (LIF). CGR8 cells were grown in a feeder-independent manner (embryonic pluripotent stem cells, ESCs) as described in protocol 1 (Fig. 1) before testing compounds of interest.

\section{CGR8 2-Luc differentiation and exposure to compounds}

To test compounds on ESC-derived neurons, neuronal differentiation was carried out as previously described (Suter et al. 2009; Xu et al. 2014). Briefly, CGR8-2Luc cells were seeded on irradiated bone marrow-derived stromal MS5 cells and cultivated for 4 days in DMEM medium containing $15 \%$ Knock-out $^{\mathrm{TM}}$ Serum Replacement, non-essential amino acids, beta-mercaptoethanol, and penicillin/streptomycin. At day 5 , cells were then re-plated $\left(3 \times 10^{5}\right.$ cells/ $\mathrm{cm}^{2}$ ) on polyornithine-coated 96-well plates in N2 medium containing DMEM, N2 supplement, penicillin/streptomycin, and $10 \mathrm{ng} / \mathrm{ml}$ basic human fibroblast growth factor (bFGF) (Invitrogen). After $48 \mathrm{~h}$ of incubation in N2 medium, abundant cells with neuron-like morphology were observed. Immunofluorescence analysis (data not shown) demonstrated that $100 \%$ of these cells were $\beta$ III tubulin-positive, as previously described (Kern et al. 2013). However, most cells did not yet stain positive for neuronal subtypes (glutamatergic neurons = vGlut (vesicular glutamate transporter), GABAergic neurons $=$ GAD67 (glutamic acid decarboxylase), cholinergic neurons $=$ ChAT (choline acetyltransferase), with the notable exception of some neurons staining for tyrosine hydroxylase (TH) (i.e., a marker of dopaminergic neurons). For toxicity testing, cells were grown for $24 \mathrm{~h}$ after replating before exposure to the respective compounds for $48 \mathrm{~h}$. Cells were lysed, 


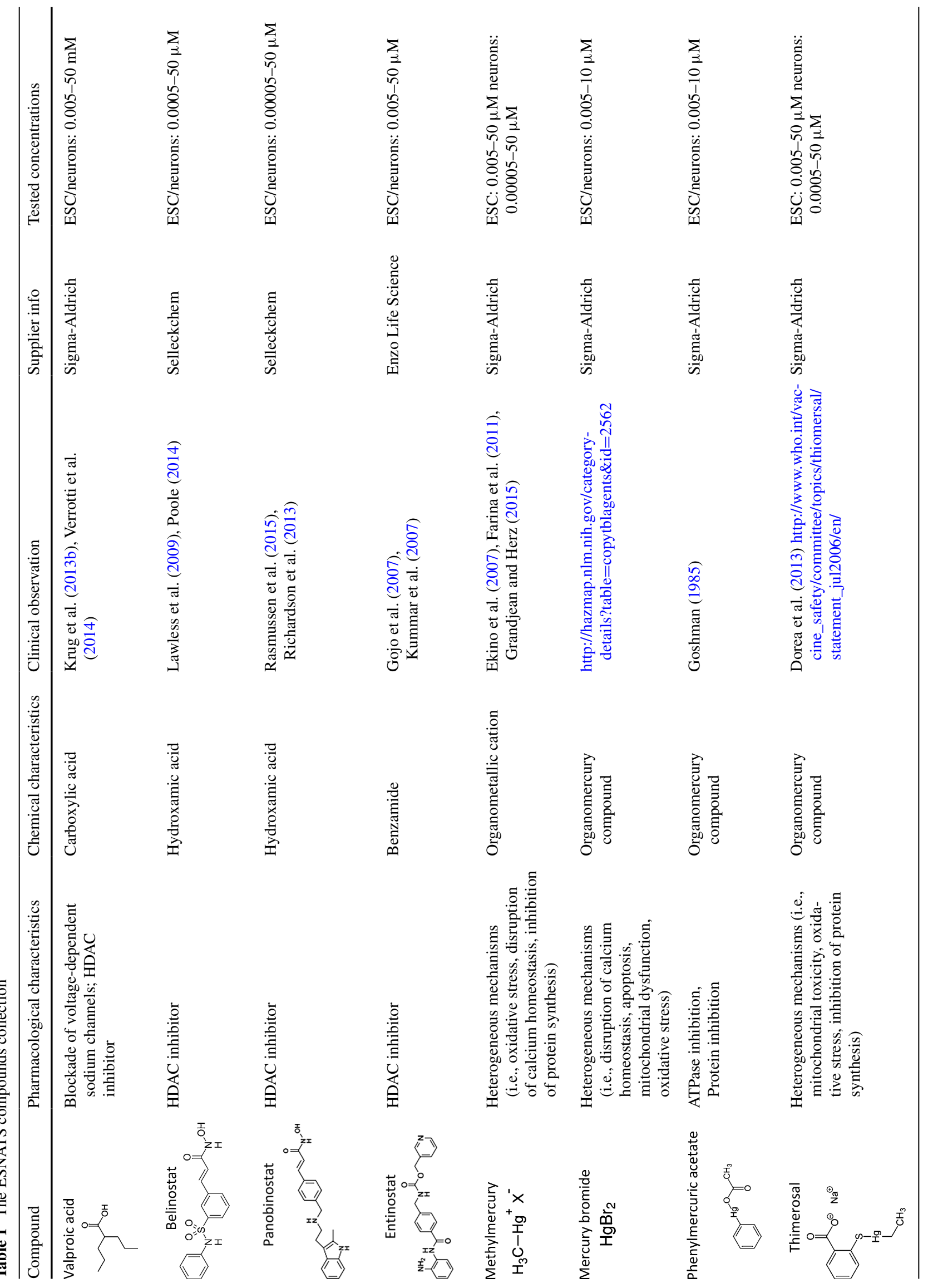




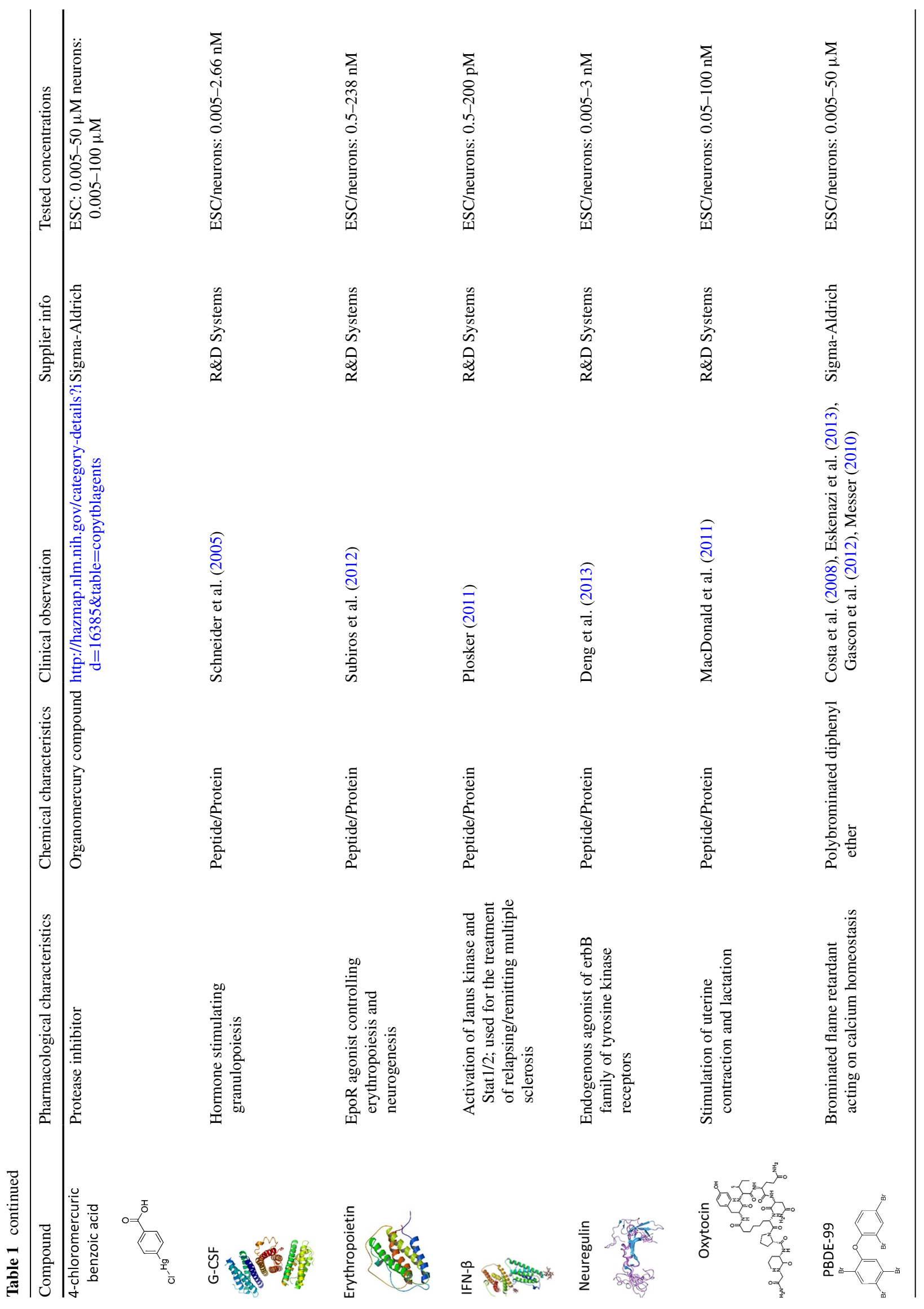




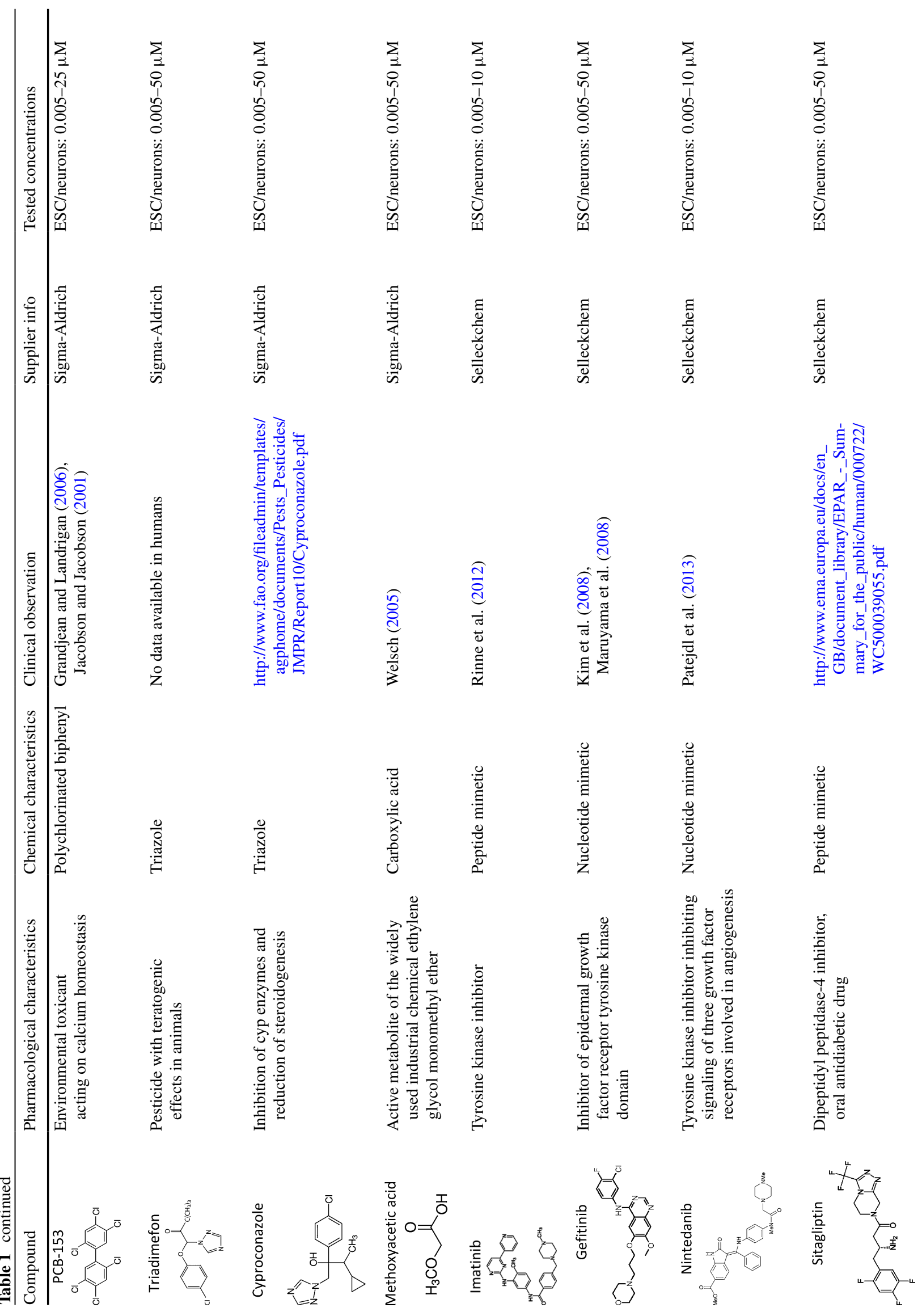




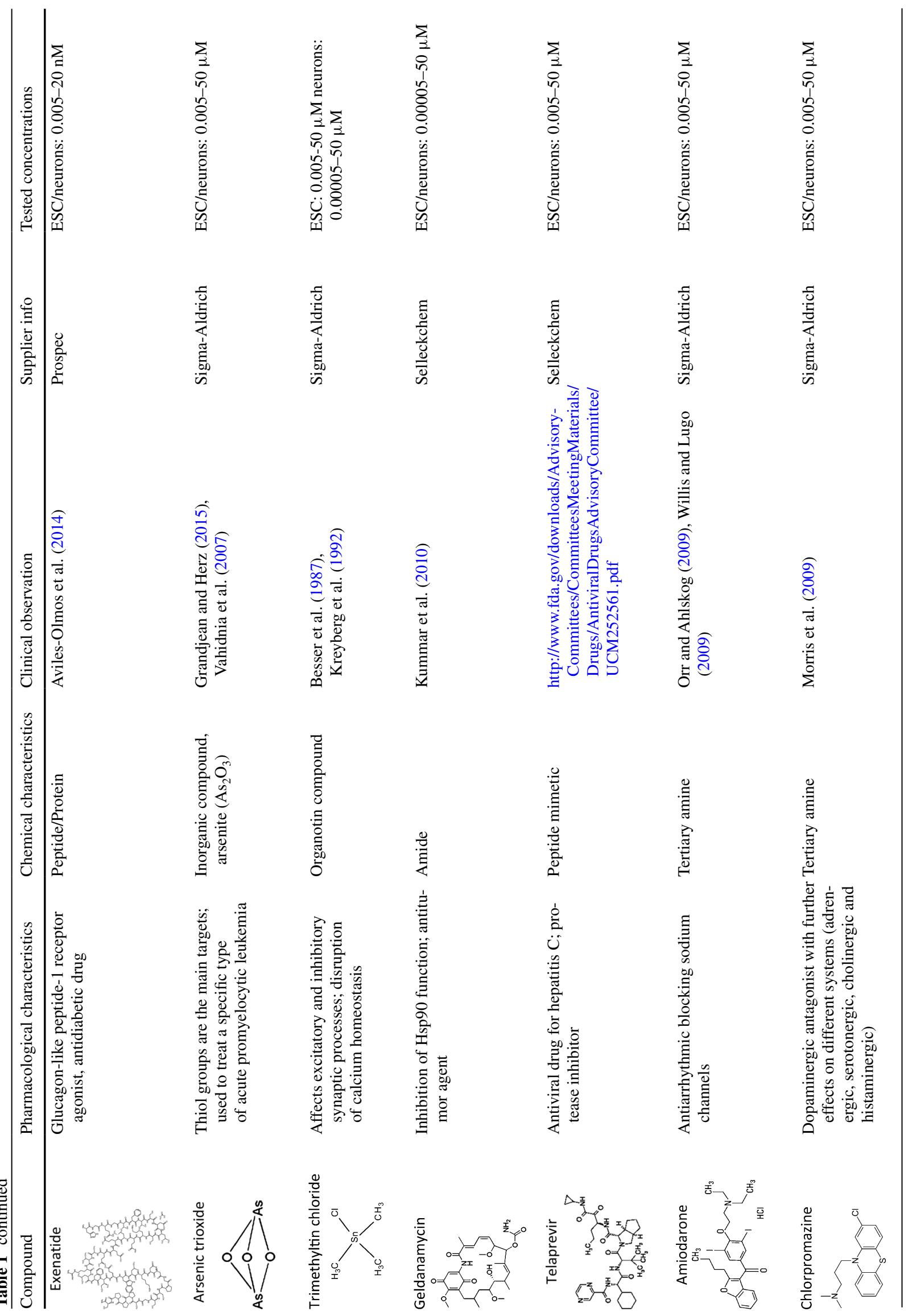




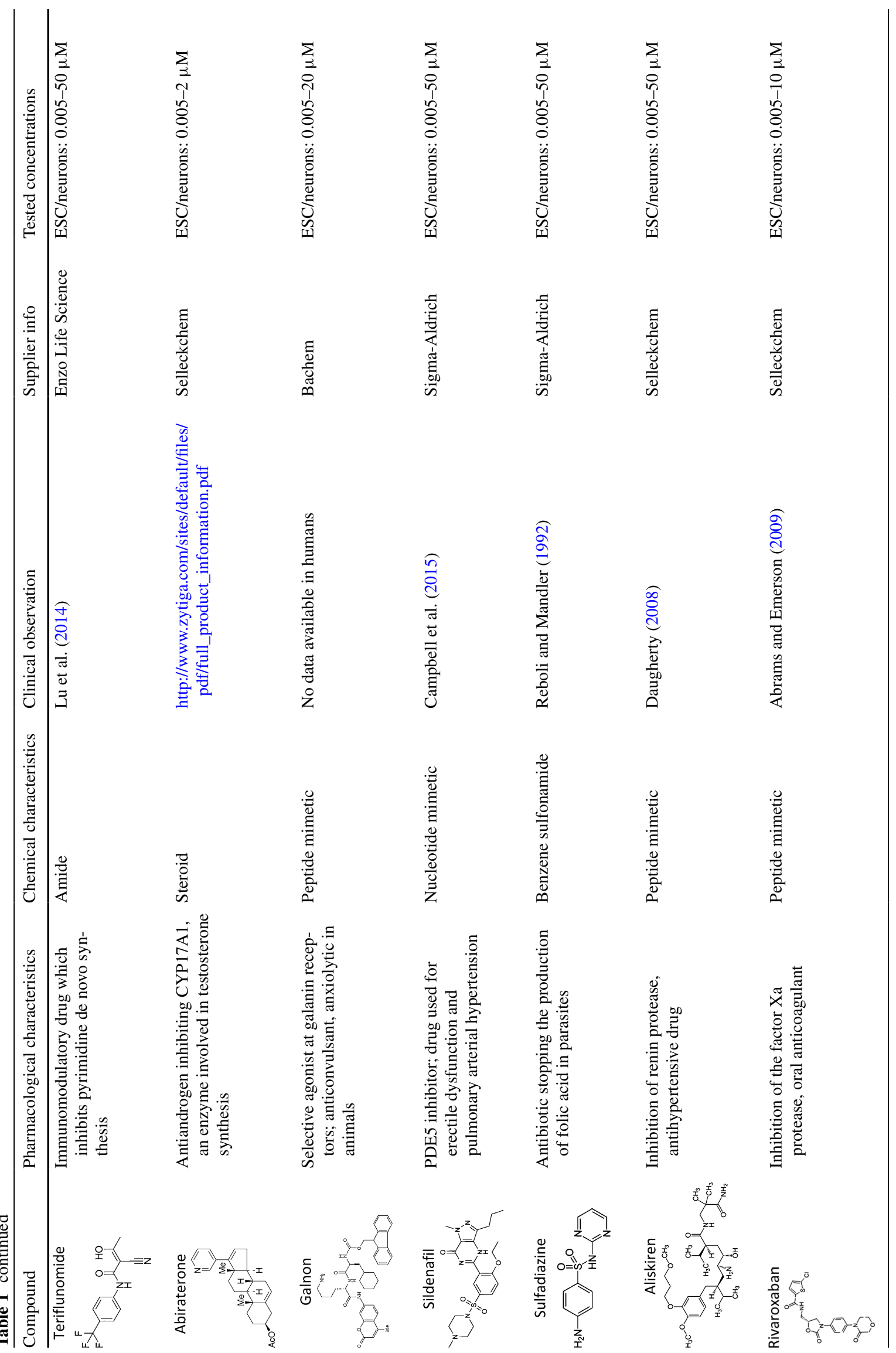


and the dual luminescence assay was performed followed by propidium iodide (PI) measurement (protocol 2, Fig. 1). To assess toxicity of compounds on undifferentiated pluripotent stem cells (ESCs), CGR8-2Luc cells were plated at 45,000 cells $/ \mathrm{cm}^{2}$ on $0.1 \%$ gelatin-coated dishes in BHK21 medium, supplemented with $10 \%$ fetal calf serum, L-glutamine, non-essential amino acids, penicillin/streptomycin, and leukemia inhibitory factor (LIF). After $24 \mathrm{~h}$, compounds were added and incubated for $48 \mathrm{~h}$, before luciferase expression and PI fluorescence were analyzed. In all experiments, methylmercury was used as a positive control at a concentration of $5 \mu \mathrm{M}$.

\section{Dual luminescence assay}

Luciferase activities were measured with a Dual-Luciferase $^{\mathrm{TM}}$ Reporter system kit. CGR8-2Luc ES cells were lysed in 96-well plates according to the manufacturer's instructions. Luminescence measurements were performed on a Fluostar Optima reader. Luminescence counts were expressed as percentage of promoter activity normalized by comparison with the control wells treated by DMSO. High standard deviation (SD) observed in RLuc values is explained by the very low expression of the general promoter in neurons. Two parameters were measured in homogenates of ESCs and in ESC-derived neurons: (1) FLuc, reflecting the activity of early neural promoter Ta1. FLuc increases during neuronal differentiation. Many neurotoxic compounds may affect FLuc expression, either through impact on neuronal differentiation, through changes of neuronal gene expression, or through killing of neurons. Note, however, that in some cases, there may be an increase of FLuc expression through potential neurotoxicants (Kern et al. 2013); (2) RLuc, reflecting the activity of the ubiquitous promoter EF1 $\alpha$. Note that in previous studies we have shown that this promoter activity markedly decreased during cellular differentiation and it can therefore not be used as a house-keeping gene to approximate the cell numbers during cellular differentiation.

\section{Propidium iodide (PI) assay}

After measurement of luciferase activity, DNA quantity was determined by PI assay, as previously described (Xu et al. 2014). PI was added to cell homogenates after the luciferase test, at a final concentration of $50 \mu \mathrm{g} / \mathrm{ml}$ and incubated for $2 \mathrm{~h}$. After incubation, fluorescence intensity was measured on a Flexstation 3 microplate reader (Excitation: $544 \mathrm{~nm} \pm 15 \mathrm{~nm}$; Emission: $620 \mathrm{~nm} \pm 15 \mathrm{~nm}$ ). Results are expressed as percentage of control. Propidium iodide (PI) measures total DNA content as an approximation of the cell number. A decrease in PI fluorescence was interpreted as a decrease in cell number and therefore throughout the

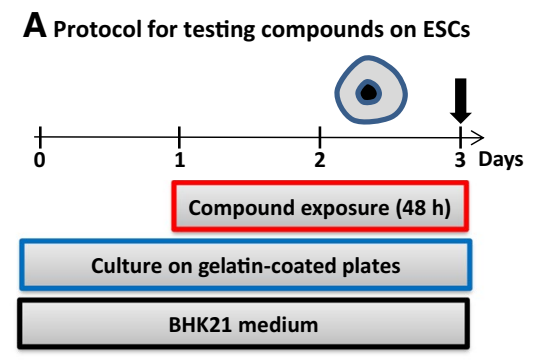

B Protocol for testing compounds on ESC-derived neurons

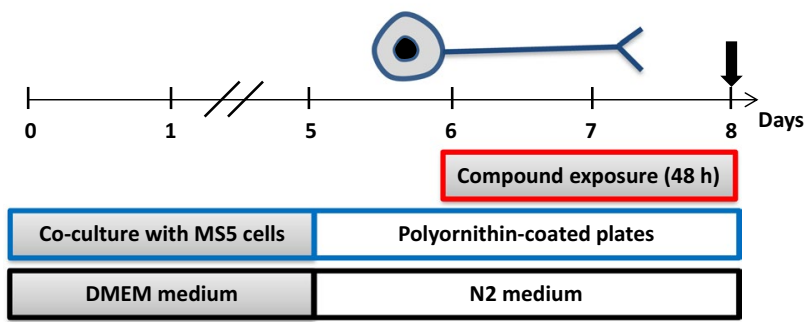

Fig. 1 Synopsis of experimental protocols. The impact of compounds on neural promoter activity (FLuc, Firefly Luciferase under the control of the T $\alpha 1$ promoter), general promoter activity (RLuc, Renilla Luciferase under the control of the EF1 $\alpha$ promoter), and amount of DNA (PI, propidium iodide fluorescence in cell homogenates) was investigated in undifferentiated mouse embryonic pluripotent stem cells (ESCs) and on ESC-derived neurons. Arrows indicate the time of measurement of the three parameters. a Protocol for testing compounds effects on ESCs. CGR8-2Luc cells were plated on gelatin-coated 96-well plates in maintenance medium (BHK21 medium containing $10 \%$ FCS, L-glutamine, NEAA, P/S, and LIF). Twenty-four hours later, cells were exposed to compounds for fortyeight hours. b Protocol for testing compounds on ESC-derived neurons. CGR8-2Luc cells were co-cultured with MS5 cells to induce neural differentiation in DMEM medium containing $15 \% \mathrm{KO}$-serum, NEAA, $\beta$-mercaptoethanol, and P/S. On day 5, cells were detached and seeded on polyornithine-coated plates in DMEM medium containing N2 supplement, bFGF, and P/S; compound exposure was from day 6 to day 8

text referred to as cytotoxicity. Note that none of the compounds led to an increase in PI fluorescence.

\section{Statistical analysis}

Luminescence counts were expressed as percentage of promoter expression normalized by comparison with the control wells treated by DMSO. PI results are expressed as percentage of control. For outlier analysis, we performed the Grubbs' test. The results were analyzed using GraphPad Prism 6 software (GraphPad Software, San Diego, CA).

\section{Assay performance and plate acceptance criteria}

To monitor assay sensitivity, S/B ratios were calculated as mean of negative control signal/mean of positive control. Mean, SD, and coefficient of variation (CV) for each signal 
(positive and negative controls) were computed. As acceptance criteria, we set a maximum CV of each signal at $20 \%$. To evaluate the robustness of each assay, we assessed the $Z$ value and the Signal Window (SW) calculated according to the following equations: $Z=1-(3 \mathrm{SD}$ of negative control +3 SD of positive control)//(mean of positive control-mean of negative control $) \mid$ and $\mathrm{SW}=(($ mean negative control-3SD negative control $/ \sqrt{ } n)$-(mean positive control +3 SD positive control $/ \sqrt{ } n)) /(\operatorname{SD}$ negative control $/ \sqrt{ } n$ ) (Iversen et al. 2012; Perrin et al. 2006), where $n$ is the number of replicates of the test substance that has been used in our assay. As acceptance criteria, we chose $\mathrm{SW} \geq 3$ and $Z \geq 0.4$ on all plates.

\section{Characterization of concentration-response curves}

To describe the shape of different concentration-response curves, arbitrary scores were assigned as follows: 0 for "no change," 1 for "down-stroke," 2 for "bimodal profile," and 3 for "up-stroke" (Fig. S1). A curve was classified as "down-stroke" or "up-stroke" if the change in response values comparative to control was statistically significant ( $p$ value $<0.05$, one-way ANOVA with post hoc Dunnett) with an additional requirement of a $30 \%$ decrease or increase of mean response value relative to controls, respectively. If the absolute change in mean response values was below $30 \%$ the curve was classified as "no change." A curve was classified as "bimodal" if first up-stroke and subsequently downstroke was observed.

\section{LOAEL evaluation}

Lowest adverse effect level (LOAEL) was defined as the lowest tested concentrations that lead to a statistically significant decrease for a given read-out (FLuc, RLuc, and PI) compared to baseline. "Baseline" was not in all cases defined by untreated cells, but may also refer to, e.g., a state of increased activity due to low, non-toxic compound concentrations.

\section{In vitro-in vivo comparison of toxicity data by PBPK modeling}

To evaluate the human relevance of in vitro concentrations found to be toxic in this study, an in vitro-in vivo comparison of the toxicity data was performed using a physiology-based pharmacokinetic (PBPK) reverse modeling approach. In particular, the following steps were taken: (a) data mining to find published studies reporting relevant concentrations inducing (neuro-) developmental toxicity in vivo or reporting relevant therapeutic concentrations reached in humans during clinical studies (when possible); (b) extraction of pharmacokinetic (PK) parameters from published studies in rats or humans and use of these data to calculate free plasma concentrations; (c) calculation of the nominal in vitro concentrations equivalent to the concentrations predicted in vivo (NEC), determined by correcting for the differences in albumin concentration and lipid fraction between plasma and test medium, using the following equation:

$\mathrm{NEC}=E C_{p l} \times\left\{\left(1-f_{b, p l}\right) \times \frac{1+K o w \times V F_{L, x}}{1+K o w \times V F_{L, p l}}+f_{b, p l} \times \frac{P_{x}}{P_{p l}}\right\}$

where $E C_{p l}$ is the effective plasma concentration; $f_{b, p l}$ corresponds to the plasma bound fraction; $K_{o w}$ is the octanol:water partition coefficient; $V F_{L}$ is the volume fractions of lipids; $P$ corresponds to the albumin concentration (or total protein concentration when indicated); and the suffix " $p l$ " and " $x$ " are indicating plasma and one of the media used in this study (Gulden and Seibert 2003) (Fig. 7). The lipid content and albumin concentrations of the test media $\mathrm{N} 2$ and BHK medium were calculated on the basis of the available information provided by the suppliers (Fig. S2A). The data on rat plasma have been adopted from (Verwei et al. 2006). The original references are (Barber et al. 1990) for albumin and (DeJongh et al. 1997) for lipids. Human plasma values were taken from (Gulden and Seibert 2003). The original data on albumin are from (Lindup 1987) and for lipids from (Patterson et al. 1988). Total protein concentrations were calculated based on the assumption that the protein molar mass is similar to the one of albu$\min (66 \mathrm{kDa})$. Albumin was assumed to represent 60 and $48 \%$ of the total serum proteins $(\mathrm{mg} / \mathrm{ml})$ in human and rat (Baker et al. 1979; Busher 1990) (Fig. S2A).

\section{In vitro-in vivo comparison of toxicity/clinical data for abiraterone}

(a) Developmental toxicity (DT) - inducing concentrations were extrapolated from the in vivo study reported in the document by the Australian Therapeutic Goods Administration (Australian Therapeutic Goods Administration 2014). In an embryo-fetal developmental toxicity study in rats, abiraterone acetate induced developmental toxicity when administered at oral doses of 10,30 or $100 \mathrm{mg} /$ $\mathrm{kg} /$ day throughout the period of organogenesis (gestational days 6-17). Findings include embryo-fetal lethality (increased postimplantation loss and decreased number of living fetuses), fetal developmental delay (skeletal effects), and urogenital effects (bilateral ureter dilation) at doses $\geq 10 \mathrm{mg} / \mathrm{kg} / \mathrm{day}$ (Australian Therapeutic Goods Administration 2014). (b) Toxicokinetic parameters of abiraterone in rats were extracted from the available report from the TGA (Australian Therapeutic Goods Administration 


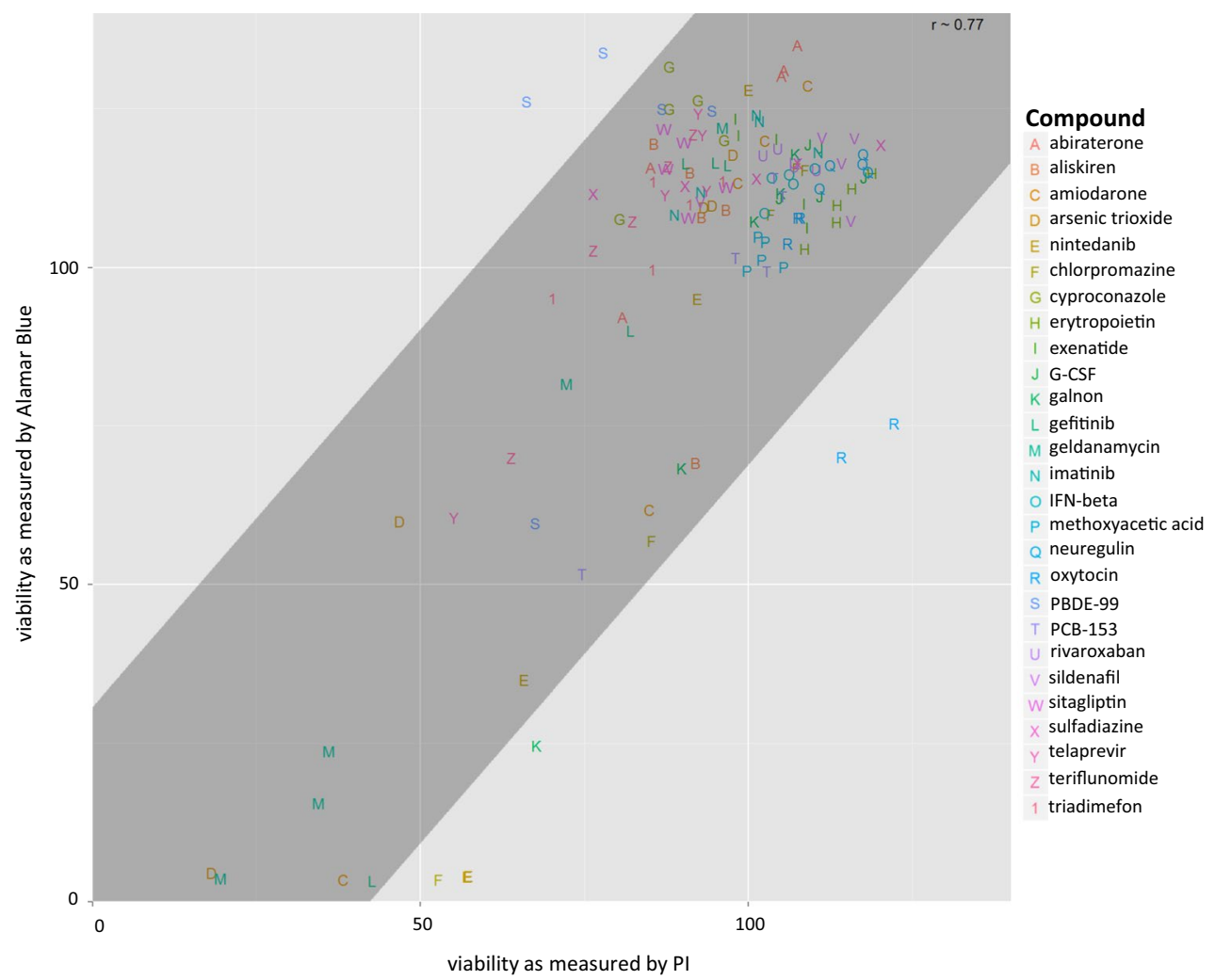

Fig. 2 Comparison of two viability assays. To validate the PI assay in the context of toxicity assessment, the cells were exposed to compounds with varying concentrations where the viability of the cells was measured with PI and Alamar Blue assays. The correlation between the two viability assays, that included all compounds and all

2014). The maximal concentration (Cmax) and AUC at the toxic dose level $(10 \mathrm{mg} / \mathrm{kg} /$ day $)$ in rats was $10.8 \mathrm{ng} /$ $\mathrm{ml}$ and $34 \mathrm{~h} * \mathrm{ng} / \mathrm{ml}$, respectively. The toxicokinetic parameters of abiraterone in humans were extracted from the study by (Goldberg and Berrios-Colon 2013); in this clinical research, a daily oral dose of $1000 \mathrm{mg} / \mathrm{kg}$, administered as abiraterone acetate and bioactivated by hydrolysis to abiraterone, led to a Cmax of $226 \mathrm{ng} / \mathrm{ml}$ and an AUC at steady state of $1173 \mathrm{~h} * \mathrm{ng} / \mathrm{ml}$. The average concentration (Cavg) was calculated from the ratio of AUC and the dose interval $(\tau)$ of $24 \mathrm{~h}$. The percentage of plasma protein binding of the drug was reported as being $99.8 \%$, without relevant species differences occurring (US FDA 2011). (c) The nominal in vitro concentrations equivalent to the concentration used in vivo were calculated using the value of total protein concentration instead of albumin concentration. This approach was chosen because abiraterone shows extreme lipophilicity and extensive protein binding in vivo; this evidences lead to the assumption that in the absence of albumin and $\alpha 1$-acid glycoprotein in the test medium, abiraterone would bind to other present proteins (Fig. S2B). concentrations, was calculated using Pearson's correlation. The correlations for each individual data point were plotted, i.e., not the IC50s, but several concentrations for each compound. In addition a linear regression model was fit to the data where the gray box indicates the 2 standard deviation of the residuals from the regression line

\section{In vitro-in vivo comparison of data for geldanamycin (GA)}

(a) No developmental toxicity studies were found for GA in vivo, but different studies reported effects of this drug on neurodifferentiation. We used the study of (Sun et al. 2012) to define a dose that is acting on neurons in vivo. A GA dose of $0.2 \mathrm{mg} / \mathrm{kg} /$ day affected nerve recovery in a model based on Thy1-GFP transgenic rats, in which the green fluorescent protein GFP was expressed under the neuronspecific promoter Thy 1 , allowing to determine the rate of axon regeneration after a nerve injury.

(b) Very few PK data are available for GA. The aqueous solubility of GA is poor, limiting the routes of administration to intravenous and intracerebroventricular. The i.v. PK of GA was studied in mice and dogs (Supko et al. 1995). At the maximum tolerated dose, plasma levels rapidly declined to below-effective concentrations in both species. Interspecies differences in PK in this study limit its usability to estimate rat PK. Based on the initial volume of distribution in mouse of $0.16 \mathrm{l} / \mathrm{kg}$, the dose of $0.2 \mathrm{mg} / \mathrm{kg}$ (rat study) would lead to a Cmax of $1.25 \mathrm{mg} / \mathrm{l}$. Supko el al 
Fig. 3 Effect of well-known non-neurotoxic and cytotoxic controls. Cells were exposed to compounds for $48 \mathrm{~h}$; neural $(\mathrm{T} \alpha 1 ;$ FLuc) and general (EF1 $\alpha$; RLuc) promoter activities and DNA quantity (PI assay) were determined. Results were expressed as percent of control + SD. Mean control values $(100 \%)$ are shown as dotted line; the SD of control values is shown as gray area. Data points that differ in a statistically significant manner from control values were determined by oneway repeated-measures ANOVA followed by Dunnett's post hoc test and are shown as filled circles. Data were obtained from 4 to 6 replicates neural promoter (FLuc)

A D-mannitol (negative control)
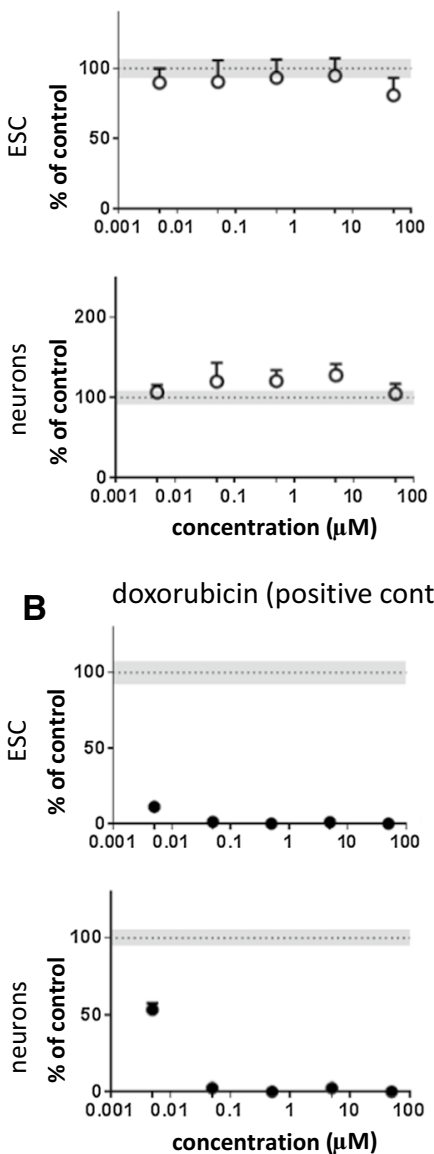

general promoter (RLuc)
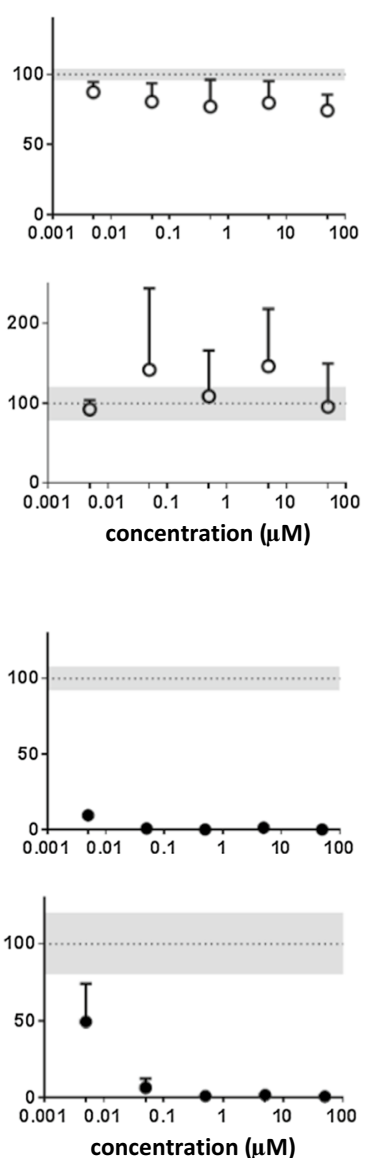

amount of DNA

(PI)
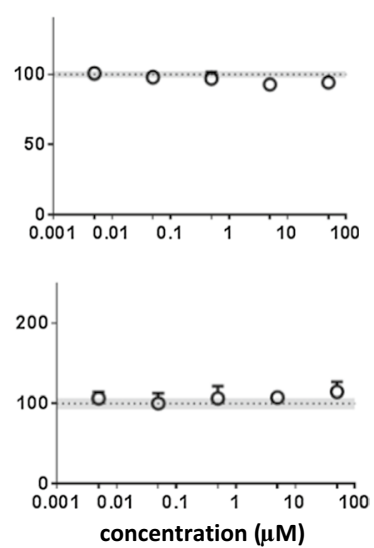

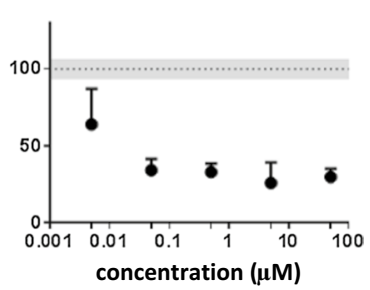

(Supko et al. 1995) noted that the low distribution volume despite its lipophilicity suggests that the compound has a much greater affinity for plasma protein than for interaction with peripheral tissue. We assumed a $f_{b, p l}$ of $99 \%$ since no more specific indications of plasma protein binding were found. (c) The nominal in vitro concentrations equivalent to the Cmax of $1.25 \mathrm{mg} / \mathrm{l}$ in rats were calculated assuming GA binding only to the specific drug-binding proteins (albumin and/or $\alpha 1$-acid glycoprotein) (Fig. S2C).

\section{In vitro-in vivo comparison of toxicity data for teriflunomide (TF)}

(a) $\mathrm{TF}$ has been showed to lead to teratogenicity when administered to Sprague Dawley rats at an oral dose of $0.3 \mathrm{mg} / \mathrm{kg} /$ day from gestational day (GD) 6 through lactational day (LD) 20. Clinical signs included malrotated forepaws/hindpaws, discoloration of the body surface, impaired coat growth, eye opacity, and eye discharge with absence of pupillary reflex were observed (US FDA 2012). (b) Assuming the toxicokinetic parameters are proportional to reported kinetics at $1 \mathrm{mg} / \mathrm{kg}$ (US FDA 2012), Cmax and
AUC at $0.3 \mathrm{mg} / \mathrm{kg}$ were estimated to be approximately $3 \mu \mathrm{g} / \mathrm{ml}$ and $33 \mathrm{~h} * \mu \mathrm{g} / \mathrm{ml}$, respectively. From the clinical point of view, a daily oral dose of $14 \mathrm{mg}$ led to a $24 \mathrm{~h}$ AUC at steady state of $1070 \mathrm{~h} * \mu \mathrm{g} / \mathrm{ml}$ in healthy individuals treated with TF (Australian Therapeutic Goods Administration 2013). The Cavg was calculated as the ratio of AUC and the dose interval $(\tau)$ of $24 \mathrm{~h}$. TF is reported to be extensively bound in plasma, probably mostly to albumin, with an average bound fraction of $99.46 \%$ (Russo et al. 2013). (c) The nominal in vitro concentrations equivalent to the concentration used in vivo in rats and humans ( $\mathrm{Cmax}$ and Cavg) were determined assuming only binding to the specific drug-binding proteins (albumin and/or $\alpha 1$-acid glycoprotein) (Fig. S2D).

\section{Results and discussion}

\section{Assay establishment}

In this study, a high-throughput dual luminescence reporter assay was established. It compares the impact of 
Fig. 4 Effect of HDAC

inhibitors and organomercury compounds. Cells were exposed to compounds for $48 \mathrm{~h}$; neural $(\mathrm{T} \alpha 1 ;$ FLuc) and general (EF1 $\alpha$; RLuc) promoter activities and DNA quantity (PI assay) were determined. Results were expressed as percent of control + SD. Mean control values (100\%) are shown as dotted line; the SD of control values is shown as gray area. Data points that differ in a statistically significant manner from control values were determined by oneway repeated-measures ANOVA followed by Dunnett's post hoc test and are shown as filled circles. Data were obtained from 4 to 8 replicates neural promoter

(FLuc)

A valproic acid
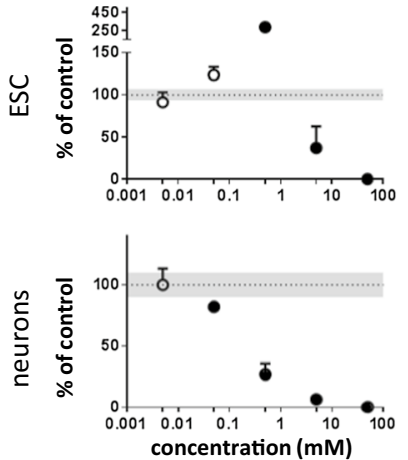

B
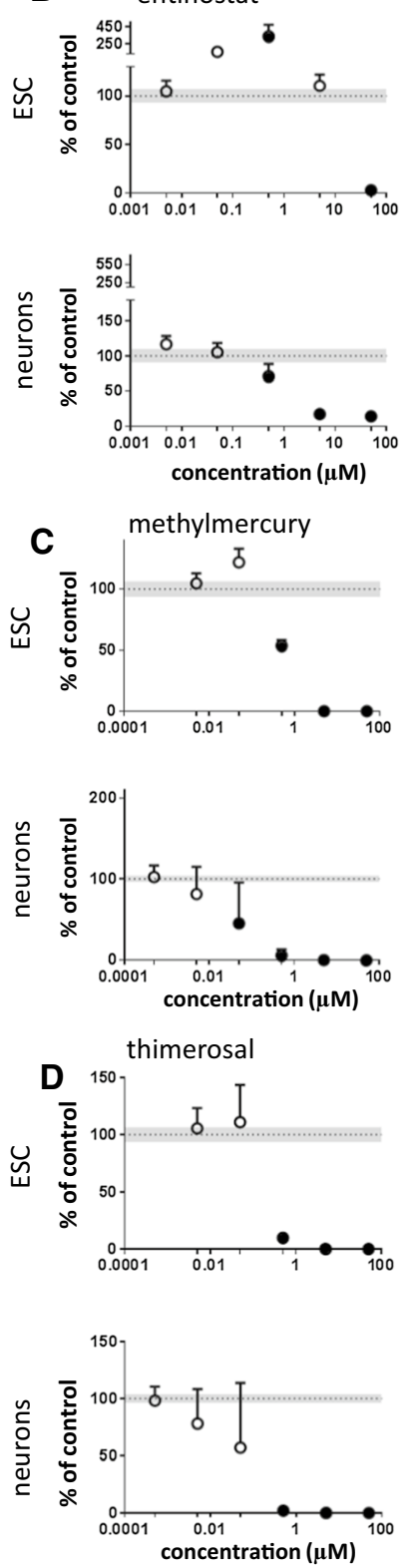

general promoter

(RLuc)

amount of DNA

(PI)
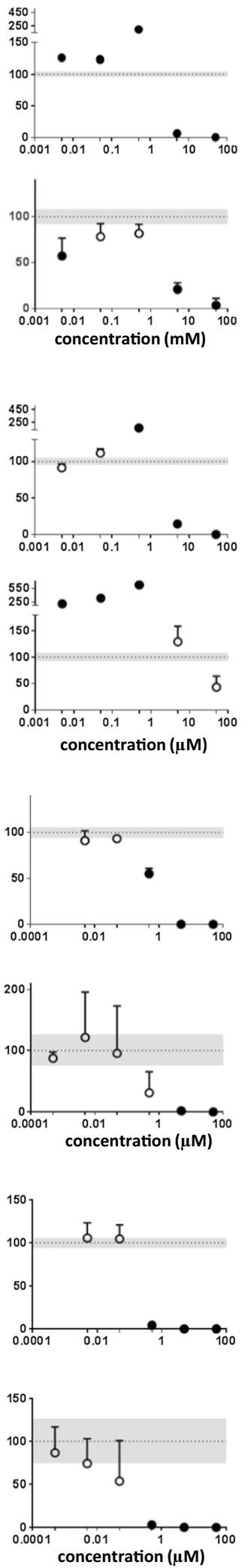
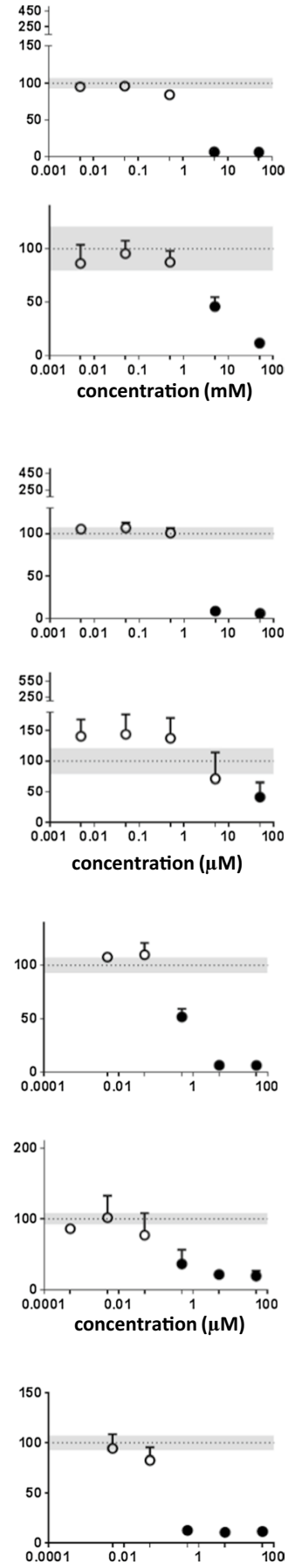

2501
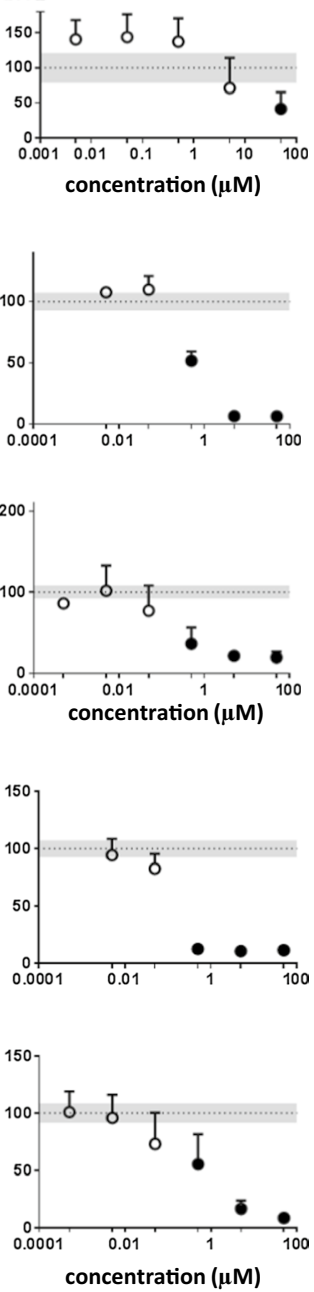
test compounds on undifferentiated pluripotent stem cells (ESCs) and ESC-derived neurons (Fig. 1). In both cell types activity of a neuron-specific promoter, tubulin $\alpha 1$ $(\mathrm{T} \alpha 1)$ and a general promoter, elongation factor $1 \alpha(\mathrm{EF} 1 \alpha)$ were determined. Moreover, total DNA content was analyzed by the PI assay as a measure of cell number. In contrast to the Alamar Blue method, a technique frequently applied in cytotoxicity testing, the PI assay can be easily integrated into the experimental procedure of the dual luminescence reporter test system. For validation of this new surrogate cytotoxicity endpoint (PI), we compared cytotoxicity data obtained by both assays, Alamar Blue and PI, using all test compounds later analyzed in this study. A high degree of correlation was found between cytotoxicity obtained by both assays (Fig. 2). Therefore, the PI assay was used in all further experiments. In a preliminary study, D-mannitol was tested as a negative control compound and compared to the cytotoxic drug doxorubicin. D-mannitol remained negative up to the highest tested concentration of $50 \mu \mathrm{M}$ for all three parameters analyzed in undifferentiated ESCs and neurons (Fig. 3a). Other non-neurotoxic controls, saccharin, ibuprofen, omeprazole, nicotinic acid, uric acid, and propranolol were studied and also yielded negative results (Fig. S3, Fig. S4). In contrast, doxorubicin strongly decreased the neuronal and general reporter activities, as well as the cell number (Fig. 3b).

\section{Response profiles in vitro and the relationship to in vivo relevant concentrations}

We next tested a set of 37 compounds to obtain an overview over concentration-response principles of the neuronal as well as the general promoter: 28 of the tested compounds belonged to the ESNATS test compound battery, including clinically used drugs (e.g., teriflunomide, abiraterone), environmental pollutants (e.g., PCB, PBDE, arsenic), and biologics (e.g., interferon- $\beta$, oxytocin). Ten further compounds were HDAC inhibitors (e.g., valproic acid, entinostat) and organomercury compounds (e.g., methylmercury, thimerosal). For some of these compounds, human data were available (Table 1) and could be used to group the compounds into three classes: strong, weak or absent neurotoxicity (Table S1).

In the dual luminescence reporter test system, all HDAC inhibitors showed cytotoxicity at their highest test concentrations as evidenced by the PI assay (Fig. 4, Fig. S5A, B). Cytotoxic effects in ESCs occurred at lower concentrations compared to neurons. At non-cytotoxic concentrations, HDAC inhibitors showed distinct effects. In undifferentiated cells, valproic acid, belinostat, and entinostat enhanced the activities of neuronal and/or general promoters (Fig. 4a, b, Fig. S5B). In contrast, in neurons, all HDAC inhibitors showed inhibition of the neural promoter at non-cytotoxic concentrations. Two of the HDAC inhibitors had slightly deviating properties. Entinostat also enhanced general promoter activity in neurons (Fig. 4b), and panobinostat showed no enhancement of promoter activities under any condition (Fig. S5A). Among the inhibitors tested, panobinostat had the most marked inhibitory effects, in particular in neurons where the neuronal promoter was inhibited at subnanomolar concentrations. Note that methoxyacetic acid is the major human metabolite of the environmental toxicant ethylene glycol monomethyl ether (EGME). It has been reported to also show some HDAC inhibitor activity (in the millimolar range). In accordance with this, it yielded only a very weak signal at the highest concentration (micromolar range) tested here (Fig. S6A). Taken together, a typical feature of HDAC inhibitors in our experimental system is their capacity to enhance promoter activities, typically at relatively low concentrations, which are presumably of relevance for in vivo neurotoxicity. The increase in both reporter gene activities could not be ascribed to an increase in cell number, as demonstrated by PI assay, but is the result of an increased promoter activity.

Among the four HDAC inhibitors tested in this study, only valproic acid was a well-characterized human developmental neurotoxicant. The other HDAC inhibitors, which are structurally unrelated to valproic acid are drugs under development for cancer indications (Cheng et al. 2015; Foss et al. 2015; Ruiz et al. 2015). In our dual luminescence reporter test system, the HDAC inhibitors shared similarities but also showed distinct features. Consistent with the role of histone acetylation in epigenetic regulation (Stefanska and MacEwan 2015; Varela et al. 2013), all HDAC inhibitors led to some degree of enhanced reporter activity. However, distinct features were the preferential effects in either ESCs as compared to neurons. Moreover, some HDAC inhibitors preferentially activated either the $\mathrm{T} \alpha 1$ or the EF1 $\alpha$ promoter. One common feature of several HDAC inhibitors is the inhibition of the T $\alpha 1$ promoter in neurons at very low concentrations. Indeed, for valproic acid, statistically significant inhibition of T $\alpha 1$-driven FLuc expression in neurons was already observed at a concentration of $50 \mu \mathrm{M}$. This concentration is of in vivo relevance, since human blood concentrations of valproic acid range between 500 and $1000 \mu \mathrm{M}$ (Krug et al. 2013b). Previous studies have shown that valproic acid inhibits neural crest cell migration in the $10-100 \mu \mathrm{M}$ range without affecting neuroepithelial precursor cell migration even at concentrations of $1 \mathrm{mM}$ (Zimmer et al. 2012). The results of valproic acid of the present study are in good agreement with previous studies performed in neuronal precursor cells derived from human embryonic stem cells (Waldmann et al. 2014). In this study, three types of impacts related to different concentration ranges have been defined: (1) a range of tolerance, observed valproic acid concentrations up to 
$25 \mu \mathrm{M}$, suggesting the existence a threshold mechanisms (Dietrich et al. 2013); (2) a deregulated/teratogenic effect was observed at concentrations between 150 and $550 \mu \mathrm{M}$ of valproic acid, which was associated with developmental disturbances, impaired cell migration, and the down-regulation of neuronal pathways (Balmer et al. 2012; Klaric et al. 2013); (3) a cytotoxic concentration range at 800 and $1000 \mu \mathrm{M}$.

While valproic acid is known as a DNT compound, methylmercury represents a model compound that triggers both developmental and adult neurotoxicity in humans and animals (Grandjean and Landrigan 2006; Kadereit et al. 2012). In the present study, four organomercury compounds have been tested (phenyl-mercuric acetate, thimerosal, 4-chloromercuric benzoic acid, and mercury bromide) in addition to methylmercury chloride. All organomercury compounds showed a very similar profile: a marked decrease in the three measured parameters, neural and general promoter activities, and total DNA content, on both ESCs and ESC-derived neurons (Fig. 4c, d, Fig. S5C, D and Fig. S7A). However, mercury bromide had less effect on neurons, as compared to ESCs. Up to concentration of $5 \mu \mathrm{M}$, neurons were not affected by mercury bromide, while the compound appeared already highly cytotoxic on ESCs at this concentration (Fig. S5C). Strong differences in the toxicities of closely related mercurials are well documented in the literature (Lohren et al. 2015; Rempel et al. 2015).

At first glance, it may seem surprising that the wellknown neurotoxicant methylmercury did not show a strong preferential neurotoxicity, as judged by comparison of its effects on the activity of the neural promoter vs the general promoter; or on comparing the toxicity to neurons vs ESCs. However, as noticed previously by others (SilvaPereira et al. 2005; Suñol and Rodríguez-Farré 2012; van Vliet et al. 2008), the in vitro toxicity of methylmercury typically includes a strong cytotoxic component. Yet, methylmercury showed a statistically significant inhibition of $\mathrm{T} \alpha 1$ promoter activity in neurons already at $0.05 \mu \mathrm{M}$, while significant changes in the other parameters and in ESCs were observed only at higher concentrations in the range between 0.5 and $5 \mu \mathrm{M}$. It should also be noted that human relevant concentrations for methylmercury are in the range of $0.005-0.5 \mu \mathrm{M}$ (Krug et al. 2013b). Thus, the influence of methylmercury on $\mathrm{T} \alpha 1$ promoter activity in neurons occurs at in vivo relevant concentrations and seems to represent an adequate marker of neurotoxicity.

Although the use of organomercury compounds such as fungicides was banned in the early 1970s (Westermark et al. 1975) and its use as an antimicrobial agent was significantly decreased or banned in many countries, mercury is currently employed as a preservative, thimerosal, in multi-dose vials of some vaccines, which are prescribed to pregnant mothers and infants (Dorea et al. 2013). It is metabolized to the cell-permeant ethylmercury in the human body and may therefore have neurotoxic effects through binding to intracellular targets. In our assay system, statistically significant effects of thimerosal on the reporter genes in neurons were observed only at concentrations of $0.5 \mu \mathrm{M}$ (Fig. 4d). In vivo, a small increase in blood mercury levels ( $<5 \mathrm{ng} / \mathrm{ml}$, which is approximatively $25 \mathrm{nM}$ ) after vaccination has been reported (Pichichero et al. 2008), which is well below the concentrations leading to statistically significant effects in our assay system. This fits well with the available epidemiological studies, which have rejected a causal relationship between thimerosal-containing vaccines and autism or neuropsychological functioning (Hurley et al. 2010; Thompson et al. 2007). Indeed, a statement was issued by the WHO in 2006 that there is no scientific evidence in favor of a neurotoxic/ DNT effect of thimerosal in babies, children, or adults exposed to the compound by way of vaccination (http:// www.who.int/vaccine_safety/committee/topics/thiomersal/ statement_jul2006/en/).

The immunomodulatory drug teriflunomide is known for its teratogenicity without documented neurotoxicity. In our experiments, it had no effects on general promoter activity and/or on PI fluorescence. However, it caused an increase in neuronal promoter activity both in neurons and in ESCs. The increase of FLuc activity may reflect its ability to enhance neural differentiation. Alternatively, it may suggest that the compound interferes with epigenetic regulation, similarly as seen above for the HDAC inhibitors. While this enhancement of promoter activity was monophasic in ESCs, it was a biphasic curve with an upstroke between 0.05 and $0.5 \mu \mathrm{M}$, followed by a downward deflection at a concentration of $50 \mu \mathrm{M}$ in ESC-derived neurons (Fig. 5a). Thus, our results suggest that at very high concentrations $(50 \mu \mathrm{M})$, teriflunomide may lead to neurotoxicity, while neurodevelopment may be affected at lower concentrations already.

Geldanamycin is a benzoquinone ansamycin antibiotic that inhibits the function of Hsp90 (Fukuyo et al. 2010). It is used as an experimental anticancer agent in animal experiments. Presently, there is no evidence for neurotoxicity of the compound. However, several previous studies have reported in vitro cytotoxicity (Clark et al. 2009; Mlejnek and Dolezel 2014; Wu et al. 2010). In our study, the compound showed a considerable cytotoxicity on neurons and on ESCs. This cytotoxicity was already observed at concentrations of $0.05 \mu \mathrm{M}$ (Fig. 5b). Thus, the main effect of geldanamycin in our experimental system is cytotoxicity, and the impact on the reporter genes should be rather considered as secondary to this cytotoxicity. Interestingly, the LD50 of geldanamycin in mice is $1 \mathrm{mg} / \mathrm{kg}$ (https:// 
Fig. 5 Representative examples of different classes of tested compounds. Cells were exposed to compounds for $48 \mathrm{~h}$; neural (T $\alpha 1 ;$ FLuc) and general (EF1 $\alpha$; RLuc) promoter activities and DNA quantity (PI assay) were determined. Results were expressed as percent of control + SD. Mean control values $(100 \%)$ are shown as dotted line; the SD of control values is shown as gray area. Data points that differ in a statistically significant manner from control values were determined by oneway repeated-measures ANOVA followed by Dunnett's post hoc test and are shown as filled circles. Data were obtained from 4 to 12 replicates neural promoter

(FLuc)

A teriflunomide
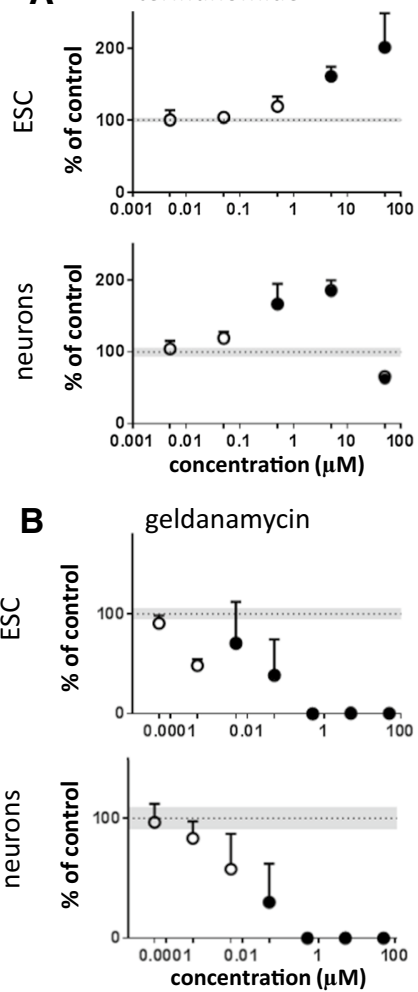

C$$
\text { 岃 }
$$
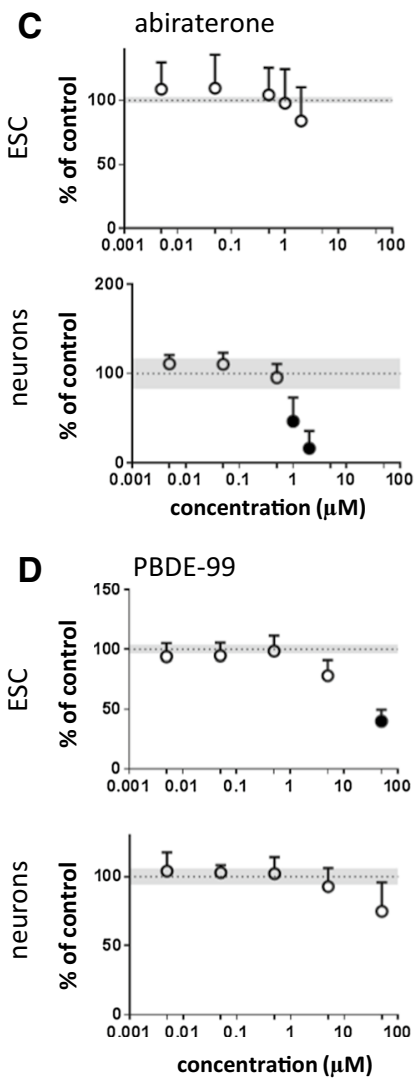

general promoter

(RLuc)
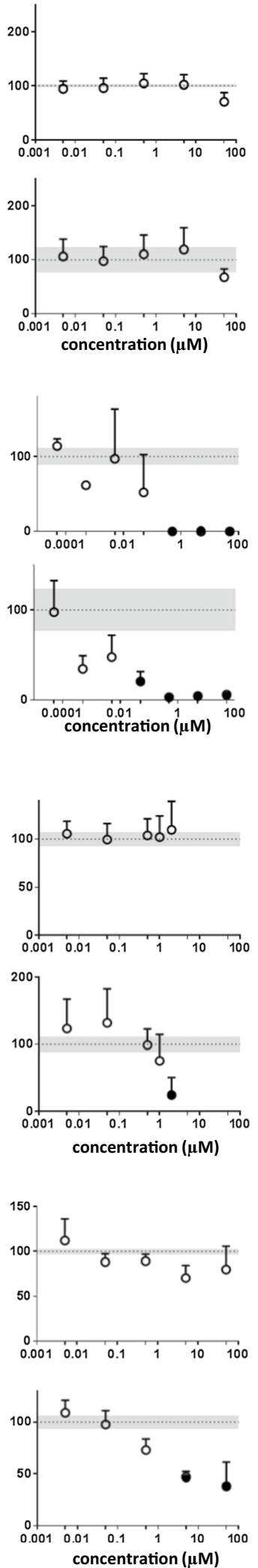

amount of DNA

(PI)
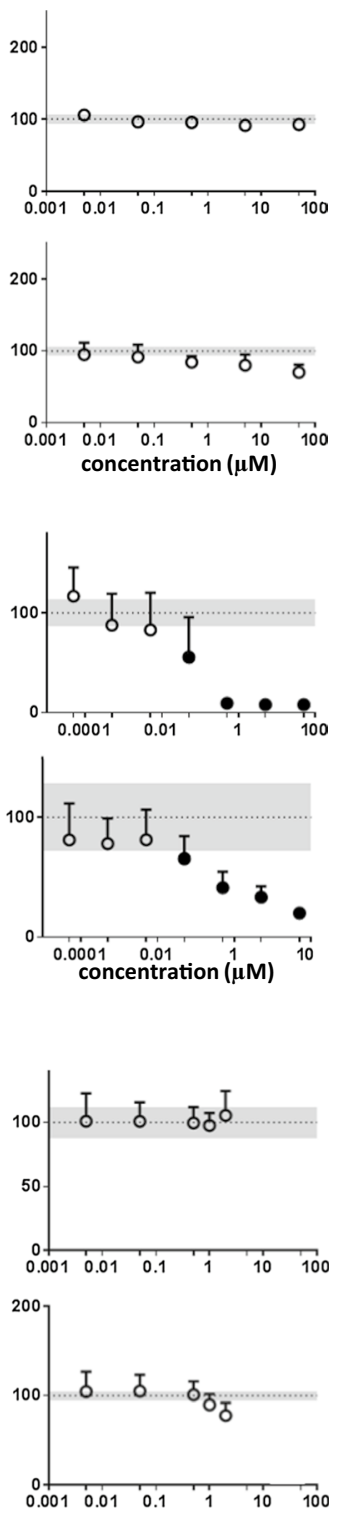

concentration $(\mu \mathrm{M})$
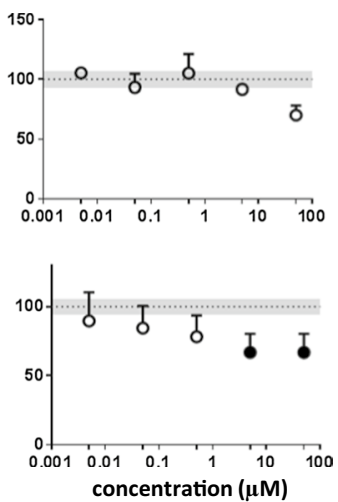


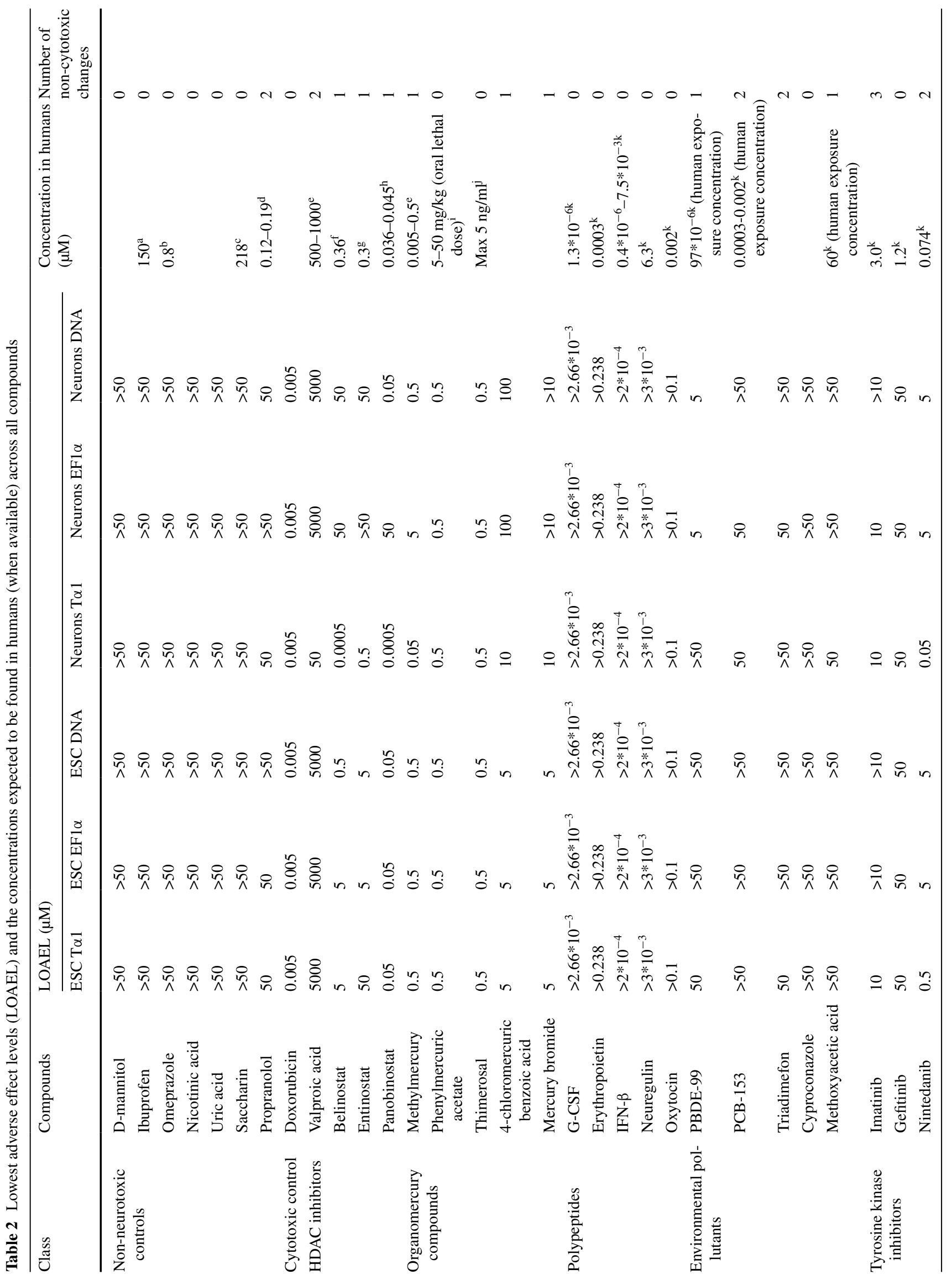




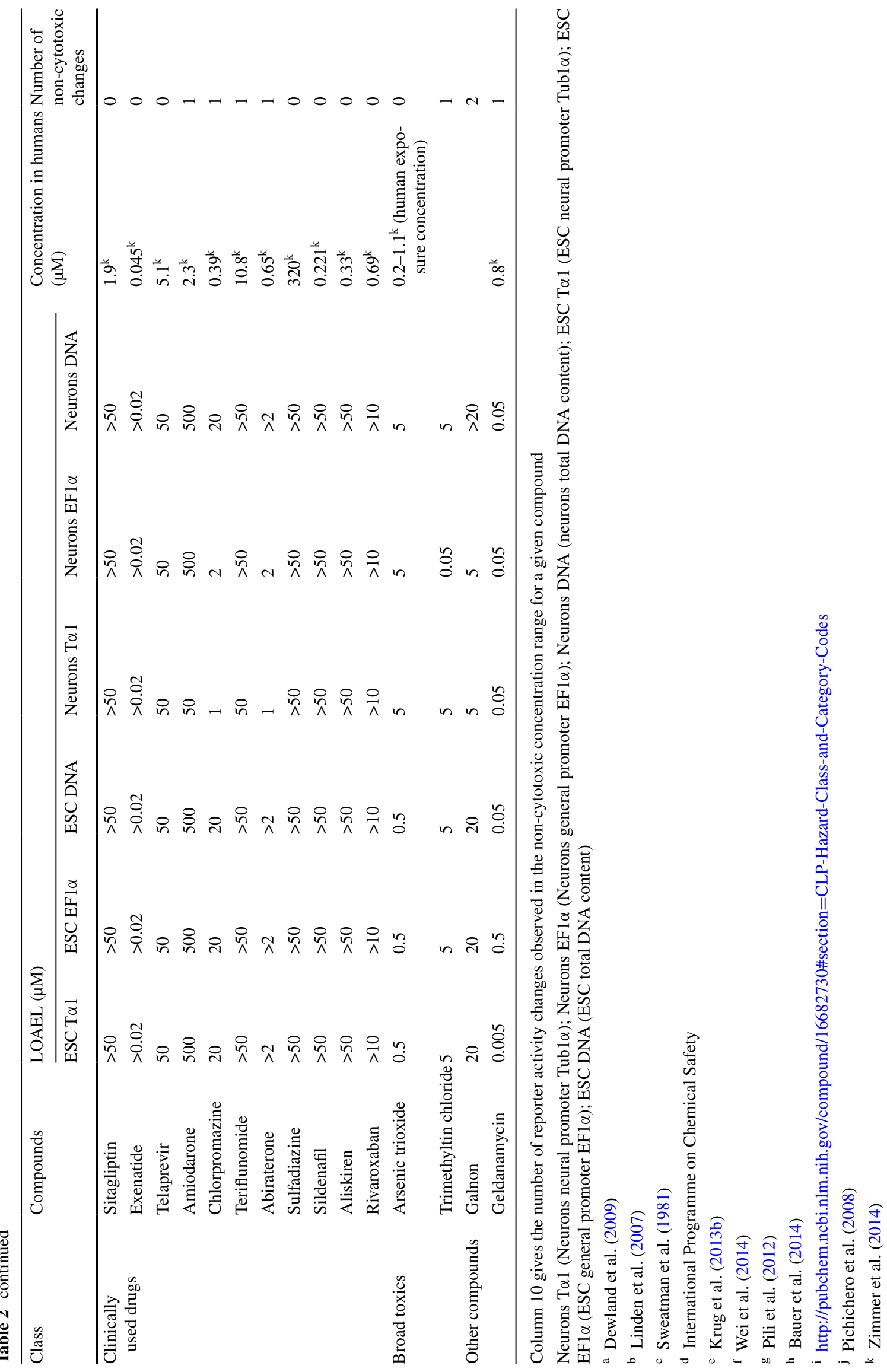


www.spectrumchemical.com/MSDS/TCI-G0334.pdf), thus relatively low and in line with the observed cytotoxicity.

Abiraterone is an anti-androgenic drug for therapy of some metastatic cancers (Patel 2013) without known neurotoxicity. Preclinical studies reported developmental toxicity in rats (Australian Therapeutic Goods Administration 2014). In our assay system, abiraterone showed no cytotoxicity up to concentrations of $100 \mu \mathrm{M}$ in the PI assay. In absence of changes in cell number, it induced a decrease of neuronal and general promoter activities in ESC-derived neurons (Fig. 5c) suggesting that at concentrations higher than $0.5 \mu \mathrm{M}$, this drug affects neural differentiation. The relationship of this concentration to clinically relevant ranges will be discussed below.

Amiodarone is a class III anti-arrhythmic drug generally prescribed for atrial fibrillation and ventricular arrhythmias. The early published experience with amiodarone suggested that neurotoxic effects such as ataxia, peripheral neuropathy, and cognitive impairment/encephalopathy were frequent (Charness et al. 1984; Greene et al. 1983). However, clinically significant neurotoxic effects seem to be observed only at high concentrations, well above those achieved with presently used drug doses (Orr and Ahlskog 2009). In a previous study searching for neurotoxic and neuroactive compounds, we observed that amiodarone clustered with other potentially neurotoxic drugs; however, only a high concentration $(10 \mu \mathrm{M})$ was tested (Kern et al. 2013). In this study, we found that the LOAEL of amiodarone in our experimental system was $5 \mu \mathrm{M}$ (FLuc in neurons; Fig. S7C, Table 2). Concentrations of amiodarone in humans have been estimated in the range of $2-3 \mu \mathrm{M}$ (Table 2). Thus, amiodarone provides an interesting example of a potentially neurotoxic compound where achievable drug levels approach the neurotoxicity threshold.

The analyzed test compound panel includes also five environmental pollutants. For three of them, PBDE-99, PCB-153, and triadimefon, evidence of neurotoxicity is available. Indeed, the dual luminescence reporter assay identified all three compounds as potentially neurotoxic (Fig. 5d, Fig. S6B,C). PBDE-99 is a flame retardant containing polybrominated diphenyl ethers (PBDEs). It easily leaches out from furniture for example, and residues have been identified in house dust and food (Frederiksen et al. 2009), as well as in human blood, adipose and placental tissues, and breast milk (Costa et al. 2008; Furst 2006; Pellacani et al. 2014). Exposure to PBDEs has been associated with developmental neurotoxicity, endocrine dysfunction, and reproductive disorders (Costa et al. 2008; Darnerud 2008; Eskenazi et al. 2013; Gascon et al. 2012). In our assay, PBDE-99 acted predominantly on neurons with moderate cell number decrease, but had a more marked effect on the general promoter activity (Fig. 5d). Human exposure concentrations are in the range of $5-100 \mathrm{pM}$ (Zimmer et al. 2014), which is below the active concentrations in the dual luminescence reporter assay seen in the present study. Future research should investigate whether long term exposure will lead to an in vitro toxicity signal at lower concentrations, or whether the effect of PBDE99 depends on co-exposure together with other congeners (Eskenazi et al. 2013; Gascon et al. 2012).

Triadimefon is largely used in agriculture as a pesticide. Studies of acute effects in rodents have indicated a potential to induce neurobehavioral effects (Crofton 1996; Reeves et al. 2004), and toxicity to the neural crest (Zimmer et al. 2012). To our knowledge, no evidence for human direct neurotoxicity is available. In the dual luminescence reporter assay, triadimefon caused only relatively weak responses (Fig. S6B) suggesting that it does not rank among the most critical compounds for murine central neurons and ESCs at the tested concentrations. Polychlorinated biphenyls (PCBs) are food contaminants widely known for their potential carcinogenic and non-carcinogenic effects (http://www.epa.gov/epawaste/hazard/tsd/pcbs/pubs/ effects.htm). In particular, a link between prenatal and postnatal exposure to PCBs and childhood cognitive function has been reported (Grandjean and Landrigan 2006; Jacobson and Jacobson 2001). In our study, the effects of PCB153 were limited to neurons where it decreased the neural and general promoter activities at the highest concentration (Fig. S6C) without affecting the number of cells.

Methoxyacetic acid is the active metabolite of the widely used industrial chemical ethylene glycol monomethyl ether (Henley and Korach 2010). This compound may have some developmental toxicity in humans (Welsch 2005). In the dual luminescence reporter assay, methoxyacetic acid showed only a relatively weak signal. At concentrations of $50 \mu \mathrm{M}$, an approximately $40 \%$ inhibition of neuronal promoter activity was seen in neurons, whereas an increase of neural promoter activity was obtained in ESCs (Fig. S6A). Given the relatively high blood concentrations of methoxyacetic acid estimated in humans exposed to the compound (Welsch 2005), our results showing statistically significant effects on the neural promoter at $50 \mu \mathrm{M}$ should be considered as a positive signal.

The antifungal agent cyproconazole is a triazole like triadimefon. It is most likely devoid of neurotoxicity (http:// www.fao.org/fileadmin/templates/agphome/documents/ Pests_Pesticides/JMPR/Report10/Cyproconazole.pdf) and did not give a signal in our assay system (Fig. S6D).

We also analyzed the effects of five polypeptides: erythropoietin, neuregulin, G-CSF, IFN- $\beta$ and oxytocin, testing concentrations in the range of reported in vivo concentrations (Table 2). Oxytocin did not have any effects in the dual luminescence reporter assay (Fig. S8A). In contrast, the four other compounds selectively increased general 


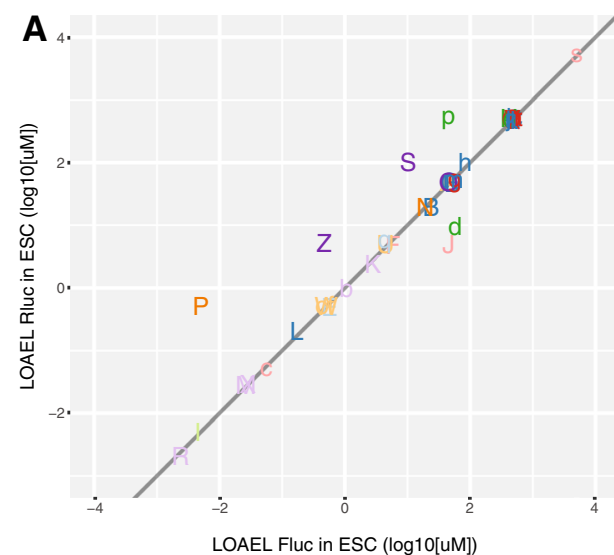

C

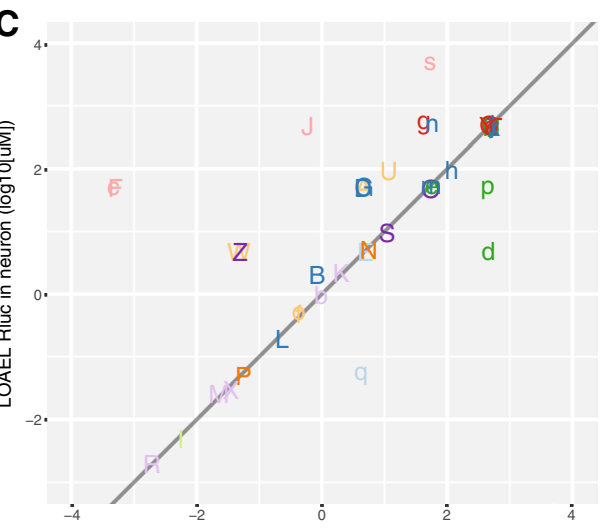

LOAEL Fluc in neuron (log10[uM])

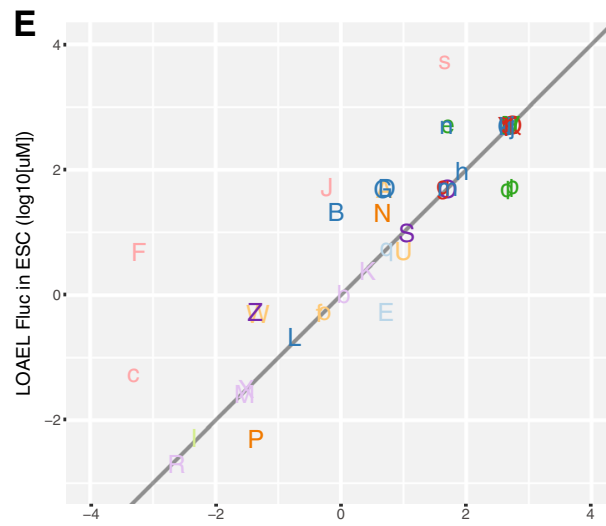

LOAEL Fluc in neuron (log10[uM])

\section{G}

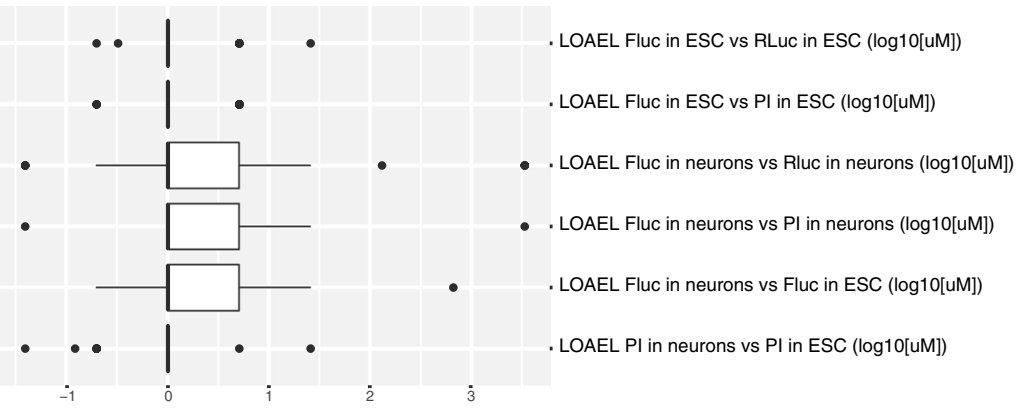

B

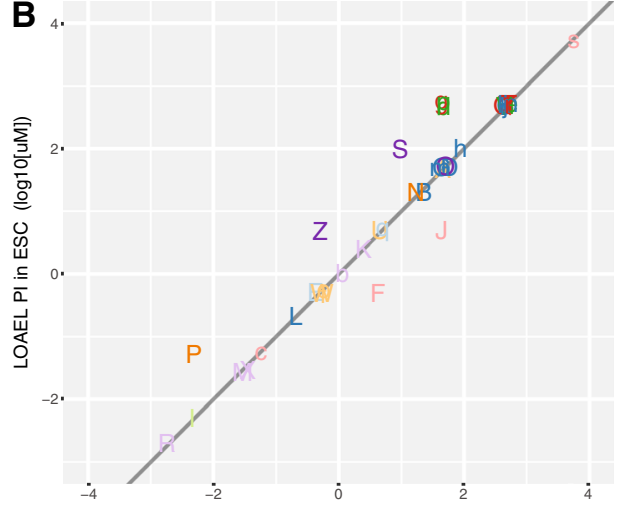

LOAEL Fluc in ESC (log10[uM])

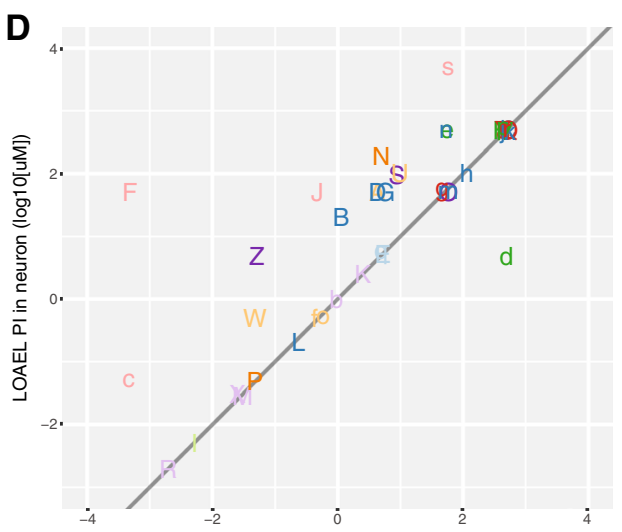

LOAEL Fluc in neuron (log10[uM])

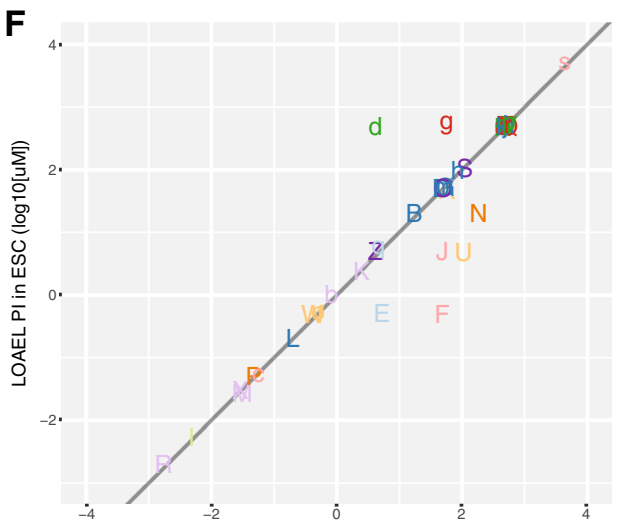

LOAEL PI in neuron (log10[uM]) broad toxic

E arsenic trioxide

q trimethyltin chloride

clinically used drugs

B abiraterone

C aliskiren

D amiodarone

$\mathrm{G}$ chlorpromazine

$L$ exenatide

h rivaroxaban

j sildenafil

k sitagliptin

I sulfadiazine

$\mathrm{m}$ telaprevir

$\mathrm{n}$ teriflunomide

cytotoxic control

doxorubicin

environmental pollutant

H cyproconazole

$\checkmark$ methoxyacetic acid

d PBDE-99

e PCB-153

$p$ triadimefon

HDAC inhibitor

$F$ belinostat

$J$ entinostat

panobinostat

S valproic acid

non-neurotoxic contro

$Q$ ibuprofen

$\mathrm{T}$ mannitol

$Y$ nicotinic acid

a omeprazole

g propranolol

i saccharin

$r$ uric acid

organomercury compounds

4-chloromercuric benzoic acid

mercury bromide

methyl mercury

phenylmercuric acetate

thimerosal

other

$\mathrm{N}$ galnon

$\mathrm{P}$ geldanamycin

polypeptides

erythropoietin

M G-CSF

R IFN-beta

neuregulin

oxytocin

tyrosine kinase inhibitors

gefitinib

$S$ imatinib

Z nintedanib 
4Fig. 6 Direct comparison of LOAELs in alert plots. a-f A scatterplot of $\log 10$ transformed lowest adverse effect levels (LOAEL). $g$ The box plot displays the distribution of distances perpendicular to the diagonal for the comparison of endpoint sensitivity of compounds. Distances of points below the diagonal are shown as negative values. Data are as in $\mathbf{a}-\mathbf{f}$

promoter activity in neurons (Fig. S8B,C,D and Fig. S9D). Also, the compounds did not affect ESCs. This is reminiscent of previous observations studying neurogenic polypeptides whose simultaneous activation of the neural and the general promoter has been described as a signature profile for growth factor-like activity (Xu et al. 2014). The absence of signs of neurotoxicity (i.e., decreased reporter activity) for these polypeptides seems plausible, given their essential role for neuronal development during embryogenesis and to neuronal function in the adult brain (Laske et al. 2009; Roysommuti et al. 2003).
Changes induced by all tested compounds on the three analyzed parameters in ESCs and in neurons are summarized in Table 2. The numbers given in column 3-8 correspond to the lowest observed adverse effect level (LOAEL), i.e., the lowest tested concentrations that caused a statistically significant decrease in a given parameter. Column 9 gives information about known concentrations that were found in humans. Column 10 gives the number of parameters changed for a given compound. The highest possible number is 4 , corresponding to the promoter activities of the two different promoters in two cell types (ESCs and neurons). A change of reporter activity in the non-cytotoxic range, as scored here, was defined as a statistically significant decrease in reporter activity without a corresponding change in PI values. Non-neurotoxic controls generally had no impact on our test systems with the exception of propranolol that caused some minor changes

A

(a) Data mining to identify in vivo DNT concentrations or therapeutic plasma concentrations (ECpl)<smiles>[CH]1[CH]C1</smiles>

(b) Extrapolation of pharmacokinetic parameters from published studies to calculate free plasma concentrations

$\downarrow$

(c) Calculation of the nominal medium concentrations EC equivalent to the concentrations found in vivo, by using the equation:

$$
\mathrm{NEC}=E C_{p l} \times\left\{\left(1-f_{b, p l}\right) \times \frac{1+K o w \times V F_{L, x}}{1+K o w \times V F_{L, p l}}+f_{b, p l} \times \frac{\mathrm{P}_{\mathrm{x}}}{\mathrm{P}_{\mathrm{pl}}}\right\}
$$

\section{B}

\begin{tabular}{|l|c|c|c|c|c|c|}
\hline & \multicolumn{2}{|c|}{$\begin{array}{c}\text { Source/ type of } \\
\text { in vivo data }\end{array}$} & $\begin{array}{c}\text { Nominal in vitro concentration } \\
\text { corresponding to in vivo } \\
\text { concentration }[\mu \mathrm{M}]\end{array}$ & \multicolumn{2}{|c|}{ In vitro EC20 $[\mu \mathrm{M}]$ in: } \\
\hline Compound & Species & $\begin{array}{c}\text { Type of } \\
\text { measurement }\end{array}$ & BHK medium & N2 medium & ESC & $\begin{array}{c}\text { ESC-derived } \\
\text { neurons }\end{array}$ \\
\hline Abiraterone & Rat & Cmax & 0.0022 & 0.0004 & 2 & 0.7 \\
\hline Abiraterone & Rat & Cavg & 0.0003 & 0.00005 & 2 & 0.7 \\
\hline Abiraterone & Human & Cmax & 0.0407 & 0.007 & 2 & 0.7 \\
\hline Abiraterone & Human & Cavg & 0.0088 & 0.0015 & 2 & 0.7 \\
\hline Geldanamycin & Rat & Cmax & 0.198 & 0.0089 & 0.01 & 0.001 \\
\hline Teriflunomide & Rat & Cmax & 0.972 & 0.0256 & $4-40$ & $10-20$ \\
\hline Teriflunomide & Rat & Cavg & 0.445 & 0.0117 & $4-40$ & $10-20$ \\
\hline Teriflunomide & Human & Cmax & 0.101 & 0.28 & $4-40$ & $10-20$ \\
\hline
\end{tabular}

Fig. 7 Reverse modeling of relevant in vivo plasma concentrations for comparison with toxic in vitro concentrations. a Outline of the workflow to determine the nominal effective concentration (NEC) in cell culture media. b Synopsis of NEC for the two media used in the study and the corresponding in vitro toxicity data (expressed as EC20) for selected compounds. NEC in embryonic pluripotent stem cells (ESCs) were compared to predicted concentrations in BHK medium; NEC in neurons were compared to predicted concentrations in N2 medium. Fields marked in green show effects in a similar concentration range (within factor 10) in in vitro tests (here) and in vivo data (literature). Abbreviations. NEC nominal effective concentration, $f b, p l$ plasma bound fraction, Kow octanol:water partition coefficient, $V F L$ volume fractions of lipids, $P$ albumin concentration (or total protein concentration); suffix " $p l$ " plasma; suffix " $x$ " type of medium used in this study (color figure online) 
at highest concentrations. An interesting exception to the rule that $\mathrm{T} \alpha 1$ promoter is most sensitive to neurotoxic insult is the impact of trimethyltin. Indeed, in neurons, the $\mathrm{EF} 1 \alpha$ promoter LOAEL was at $50 \mathrm{nM}$, as compared to a LOAEL of $5 \mu \mathrm{M}$ for T $\alpha 1$ and PI. This demonstrates that for some type of toxicants the perturbance of cellular gene expression by a well-defined neurotoxicant is more readily detected by a general promoter driving protein translation $(\mathrm{EF} 1 \alpha)$, than by the promoter driving expression of a neural-specific gene $(T \alpha 1)$. It clearly provides a justification for our dual promoter approach. Note also that in the analysis provided in this table increases in promoter activity were not included. Although these increases might be of interest for understanding mechanisms of activity of certain compounds, they did not seem to improve detection of neurotoxicants.

\section{Alert plots of neurotoxicity}

To obtain an overview over the effects induced by the test compounds, the lowest observed adverse effect concentrations (LOAEL) affecting the activities of the neuronal (FLuc) and general (RLuc) promoter were summarized in alert plots (Fig. 6). Alert plots were established separately for ESCs (Fig. 6a, b) and the derived neuronal cells (Fig. 6c, d). Analysis of ESCs resulted in a high correlation of FLuc and RLuc with data points close to the diagonal, indicating similar responses of the neuronal and the general promoter activities (Fig. 6a). A different scenario was obtained in the alert plot of the ESC-derived neuronal cells, where several compounds clustered to the upper left of the diagonal (Fig. 6c), indicating that these compounds affect the neuronal promoter at lower concentrations than the general promoter. Interestingly, well-known neurotoxicants as well as DNT compounds cluster in the upper left region, such as valproic acid and other HDAC inhibitors, and also methylmercury. Therefore, clustering of an unknown test compound to this region should be considered as a neurotoxic alert that requires further assessment. It is also of interest that for many compounds, toxicity was evident in neurons differentiated from ESCs, but not in non-differentiated ESCs. In a similar way, alert plots were set for FLuc and PI to study the relationship between neuronal promoter activation and cytotoxicity (Fig. 6b, d). Clustering to the upper left in these plots means that neuronal promoter inhibition occurs at lower concentrations than cytotoxicity. A direct comparison between LOAELs in ESCs and the derived neuronal cells was analyzed for PI (Fig. 6f) and FLuc (Fig. 6e). For PI, the measure of cytotoxicity, relatively similar results were obtained for both ESCs and neurons (Fig. 6f). In contrast, the responses for the neural promoter activity cluster to the lower right, indicating a higher sensitivity for neuronal cells compared to ESCs (Fig. 6e). Again, this increase in susceptibility of neuronal cells compared to their precursor cells was particularly pronounced for HDAC inhibitors. These alert plots of LOAELs obtained by the dual luminescence reporter assay will be helpful to obtain an overview of possible neurotoxic alerts of novel test compounds, especially since their scattering positions can now be compared to those of a number of positive and negative reference compounds.

Finally, an interesting feature of the here established dual fluorescence reporter assay is that compounds cannot only lead to a decrease in reporter gene expression, but also to an increase, or to biphasic curves where an increase is followed by a decrease. This was particularly evident for HDAC inhibitors, as well as for teriflunomide. Bimodal curves were obtained in ESCs, but a decrease of reporter activities was observed in neurons. To see whether these patterns of reporter gene expression were linked to known neurotoxicity, we analyzed the type of curve that was observed in different groups of compounds (Fig. S14). All tested clinically used compounds did not cause any positive effects in the dual luminescence reporter assay at concentrations known to occur in the blood of patients.

\section{PBPK modeling of hit compounds}

To compare the effective/toxic concentrations found in our study with relevant in vivo concentrations, we used a reverse pharmacokinetic modeling approach for three exemplary compounds: teriflunomide, geldanamycin, and abiraterone. Firstly, we used a literature data mining approach to identify toxic or clinically relevant plasma concentrations reported in published animal studies (in relation to developmental toxicity or neurotoxicity) or clinical measurements (mostly in relation to drug efficacy). Then those values were used as points-of-departure to calculate the nominal equivalent concentrations (NEC) in both cell culture media used in our study, the BHK and N2 medium. These two media (used to expose the ESCs and the ESCderived neurons) contained different amounts of protein and lipid and therefore required separate calculations of the NEC. The strategy to calculate the NEC was based on the assumption that only the free fraction of the drug (not bound to protein or lipid) is responsible for toxicity or pharmacological efficacy. Thus, free concentrations should be compared across systems, and for this it was important to calculate the NEC that would yield the same free concentration. This mathematical background is best exemplified by an example: if a drug D has clinical effects at a plasma concentration of $5 \mu \mathrm{M}$, and the free fraction is $10 \%$ in human plasma, then experimental test systems should show an effect at a free drug concentration of $0.5 \mu \mathrm{M}$, if they react in the same way as humans. The NEC is the 
nominal concentration in a given test system that produces this free drug concentration. For instance, in test system A, there may be no protein or lipid in the medium. In this case, the NEC would be equal to the free concentration, i.e., $0.5 \mu \mathrm{M}$. In test system $\mathrm{B}$, the free drug concentration may be only $1 \%$ (due to high protein content). In this system, the NEC would be $50 \mu \mathrm{M}$ (to obtain a free concentration of $0.5 \mu \mathrm{M})$. Accordingly, the different NEC were calculated for the two test systems (media) used here (Fig. 7a). For the calculation of the NEC, the parameters of lipid content (VFL) and albumin concentration (P) (or total protein concentration) were determined for each model from the literature or supplier data sheet information (Fig. S2A). The compound-specific values of plasma bound fraction and octanol:water partition coefficient were extracted from the literature to allow NEC calculation.

After the determination of the NEC, the next step of our strategy was to compare the NEC with the NOAEL for toxicity in our test systems. This procedure, and the conclusions therefrom, is detailed for the three model compounds below.

Abiraterone: a developmental toxicity study performed in rats by the Australian regulatory body for therapeutic goods, TGA (TGA 2014) and data from clinical measurements on the pharmacokinetics of abiraterone in healthy subjects (Goldberg and Berrios-Colon 2013) were used to identify relevant drug plasma concentrations. The average concentrations (Cavg) were calculated from the maximal concentration (Cmax), based on published pharmacokinetics studies. The NEC equation was finally applied as described in Materials and methods. The NEC of abiraterone in $\mathrm{N} 2$ medium was $0.05-0.4 \mathrm{nM}$ when modeled from the rat DNT exposure, and 1.5-7 $\mathrm{nM}$ when human exposure data were used. The NEC in BHK medium (ECy) was 0.3-2.2 $\mathrm{nM}$ (for DT dose exposure) and 8.8-41 nM when calculated using the clinical dose. The LOAEL of abiraterone was $0.7-2 \mu \mathrm{M}$ in neurons/ESCs. Comparison of the LOAEL and NEC shows a difference of 50-100 fold, and thus suggests that the clinical drug concentrations are far below the one causing effects in our in vitro test. Moreover, the effects observed in the rat developmental toxicity study occurred at lower concentration than the ones required to affect neurodifferentiation in our neuronal model (Fig. 7b, Fig. S13).

Geldanamycin: Data on the developmental toxicity of geldanamycin in vivo were not found, but effects on neurodifferentiation were observed in rats by Sun et al. (2012) at a dose of $0.2 \mathrm{mg} / \mathrm{kg} /$ day. Extrapolation of pharmacokinetics data from Supko et al. (Supko et al. 1995) allowed then the calculation of the Cmax and of the respective NEC.

The NEC of geldanamycin was $8.9 \mathrm{nM}$ in N2 medium and $198 \mathrm{nM}$ in BHK medium when modeled from the rat study described by Sun et al. (2012). In our in vitro system, geldanamycin showed an EC20 of 1-10 nM. The effects of geldanamycin in our in vitro model thus closely reflected the in vivo concentration range (Fig. 7b, Fig. S13).

Finally, we compared the in vitro-in vivo toxicity/ clinical data for teriflunomide. The developmental toxicity dose of the immunomodulatory drug was extrapolated from an in vivo study on the effect of teriflunomide on the offspring of drug-exposed rats (FDA 2012). Clinical pharmacokinetics information was extracted from a study on healthy individuals treated with the drug (TGA 2013). The NEC of teriflunomide in $\mathrm{N} 2$ medium was $12-26 \mathrm{nM}$ when calculated from the rat data, and $280 \mathrm{nM}$ when clinical plasma level data were used. The NEC of teriflunomide in BHK medium was 445-970 nM (for DT dose exposure) and $100 \mathrm{nM}$ when calculated using the clinical doses. In our system, teriflunomide showed various effects in a concentration range of 4-40 $\mu \mathrm{M}$. The NOAEL of teriflunomide in ESCs was in the same range (i.e., same order of magnitude) as the in vivo data, while the neuronal system was less sensitive to the drug (35 fold) (Fig. 7b, Fig. S13). These three examples indicated that NOAELs identified here may either be directly clinically relevant, be partially relevant (to create an alert), or be outside the realistic clinical range, and may therefore be neglected.

\section{Conclusion}

In this study, a tool to identify test compounds with potential neurotoxic effects has been established. This highthroughput dual luminescence reporter assay provides a biologically relevant, embryonic stem cell-based testing system, which is particularly useful for the screening of high numbers of test compounds.

Acknowledgments We thank Lasta Kocjancic Curty for technical assistance. This work was supported by the European Community's ESNATS project. SI was supported by Swiss Centre of Applied Human Toxicology (SCAHT).

Open Access This article is distributed under the terms of the Creative Commons Attribution 4.0 International License (http://creativecommons.org/licenses/by/4.0/), which permits unrestricted use, distribution, and reproduction in any medium, provided you give appropriate credit to the original author(s) and the source, provide a link to the Creative Commons license, and indicate if changes were made.

\section{References}

Abrams PJ, Emerson CR (2009) Rivaroxaban: a novel, oral, direct factor Xa inhibitor. Pharmacotherapy 29(2):167-181. doi:10.1592/ phco.29.2.167 
Australian Therapeutic Goods Administration (2013) Australian Public Assessment Report for Teriflunomide.PM-2011-02772-3; http://www.tga.gov.au/pdf/auspar/auspar-teriflunomide-130521. pdf

Australian Therapeutic Goods Administration T (2014) Australian Public Assessment Report for Abiraterone Acetate. PM-201202706-3-4;https://www.tga.gov.au/word/auspar/ausparabiraterone-acetate-140122.docx

Aviles-Olmos I, Dickson J, Kefalopoulou Z et al (2014) Motor and cognitive advantages persist 12 months after exenatide exposure in Parkinson's disease. J Parkinsons Dis 4(3):337-344. doi:10.3233/JPD-140364

Baker H, Lindsey J, Weisbroth S (1979) The laboratory rat: biology and diseases, vol 1. Academic Press, London

Bal-Price A, Crofton KM, Leist M et al (2015) International STakeholder NETwork (ISTNET): creating a developmental neurotoxicity (DNT) testing road map for regulatory purposes. Arch Toxicol 89(2):269-287. doi:10.1007/s00204-015-1464-2

Balmer NV, Weng MK, Zimmer B et al (2012) Epigenetic changes and disturbed neural development in a human embryonic stem cell-based model relating to the fetal valproate syndrome. Hum Mol Genet 21(18):4104-4114. doi:10.1093/ $\mathrm{hmg} / \mathrm{dds} 239$

Barber BJ, Schultz TJ, Randlett DL (1990) Comparative analysis of protein content in rat mesenteric tissue, peritoneal fluid, and plasma. Am J Physiol 258(5 Pt 1):G714-G718

Bauer S, Hilger RA, Muhlenberg T et al (2014) Phase I study of panobinostat and imatinib in patients with treatment-refractory metastatic gastrointestinal stromal tumors. $\mathrm{Br} \mathrm{J}$ Cancer 110(5):1155-1162. doi:10.1038/bjc.2013.826

Besser R, Kramer G, Thumler R, Bohl J, Gutmann L, Hopf HC (1987) Acute trimethyltin limbic-cerebellar syndrome. Neurology 37(6):945-950

Breier JM, Gassmann K, Kayser R et al (2010) Neural progenitor cells as models for high-throughput screens of developmental neurotoxicity: state of the science. Neurotoxicol Teratol 32(1):4-15. doi:10.1016/j.ntt.2009.06.005

Busher JT (1990) Serum albumin and globulin. In: Walker HK, Hall WD, Hurst JW (eds) Clinical methods: the history, physical, and laboratory examinations, 3rd edn. Butterworth Publishers, Boston, pp 497-499

Campbell UB, Walker AM, Gaffney M et al (2015) Acute nonarteritic anterior ischemic optic neuropathy and exposure to phosphodiesterase type 5 inhibitors. J Sex Med 12(1):139-151. doi:10.1111/jsm.12726

Charness ME, Morady F, Scheinman MM (1984) Frequent neurologic toxicity associated with amiodarone therapy. Neurology 34(5):669-671

Cheng T, Grasse L, Shah J, Chandra J (2015) Panobinostat, a panhistone deacetylase inhibitor: rationale for and application to treatment of multiple myeloma. Drugs Today (Barcelona) 51(8):491-504. doi:10.1358/dot.2015.51.8.2362311

Clark CB, Rane MJ, El Mehdi D, Miller CJ, Sachleben LR Jr, Gozal E (2009) Role of oxidative stress in geldanamycininduced cytotoxicity and disruption of Hsp90 signaling complex. Free Radic Biol Med 47(10):1440-1449. doi:10.1016/j. freeradbiomed.2009.08.012

Clarkson TW, Strain JJ (2003) Nutritional factors may modify the toxic action of methyl mercury in fish-eating populations. $\mathrm{J}$ Nutr 133(5 Suppl 1):1539S-1543S

Coecke S, Goldberg AM, Allen S et al (2007) Workgroup report: incorporating in vitro alternative methods for developmental neurotoxicity into international hazard and risk assessment strategies. Environ Health Perspect 115(6):924-931. doi:10.1289/ehp. 9427
Costa LG, Giordano G, Tagliaferri S, Caglieri A, Mutti A (2008) Polybrominated diphenyl ether (PBDE) flame retardants: environmental contamination, human body burden and potential adverse health effects. Acta Biomed 79(3):172-183

Crofton KM (1996) A structure-activity relationship for the neurotoxicity of triazole fungicides. Toxicol Lett 84(3):155-159

Darnerud PO (2008) Brominated flame retardants as possible endocrine disrupters. Int $\mathrm{J}$ Androl 31(2):152-160. doi:10.1111/j.1365-2605.2008.00869.x

Daugherty KK (2008) Aliskiren. Am J Health Syst Pharm 65(14):1323-1332. doi:10.2146/ajhp070529

Davidson PW, Myers GJ, Weiss B (2004) Mercury exposure and child development outcomes. Pediatrics 113(4 Suppl):1023-1029

DeJongh J, Verhaar HJ, Hermens JL (1997) A quantitative propertyproperty relationship (QPPR) approach to estimate in vitro tissue-blood partition coefficients of organic chemicals in rats and humans. Arch Toxicol 72(1):17-25

Deng C, Pan B, Engel M, Huang XF (2013) Neuregulin-1 signalling and antipsychotic treatment: potential therapeutic targets in a schizophrenia candidate signalling pathway. Psychopharmacology 226(2):201-215. doi:10.1007/s00213-013-3003-2

Dewland PM, Reader S, Berry P (2009) Bioavailability of ibuprofen following oral administration of standard ibuprofen, sodium ibuprofen or ibuprofen acid incorporating poloxamer in healthy volunteers. BMC Clin Pharmacol 9:19. doi:10.1186/1472-6904-9-19

Dietrich DR, von Aulock S, Marquardt H et al (2013) Scientifically unfounded precaution drives European Commission's recommendations on EDC regulation, while defying common sense, well-established science and risk assessment principles. ALTEX 30(3):381-385

Dorea JG, Farina M, Rocha JB (2013) Toxicity of ethylmercury (and Thimerosal): a comparison with methylmercury. J Appl Toxicol 33(8):700-711. doi:10.1002/jat.2855

Ekino S, Susa M, Ninomiya T, Imamura K, Kitamura T (2007) Minamata disease revisited: an update on the acute and chronic manifestations of methyl mercury poisoning. J Neurol Sci 262(1-2):131-144. doi:10.1016/j.jns.2007.06.036

Eskenazi B, Chevrier J, Rauch SA et al (2013) In utero and childhood polybrominated diphenyl ether (PBDE) exposures and neurodevelopment in the CHAMACOS study. Environ Health Perspect 121(2):257-262. doi:10.1289/ehp.1205597

Farina M, Rocha JB, Aschner M (2011) Mechanisms of methylmercury-induced neurotoxicity: evidence from experimental studies. Life Sci 89(15-16):555-563. doi:10.1016/j. lfs.2011.05.019

Foss F, Advani R, Duvic M et al (2015) A phase II trial of Belinostat (PXD101) in patients with relapsed or refractory peripheral or cutaneous T-cell lymphoma. Br J Haematol 168(6):811-819. doi:10.1111/bjh.13222

Frederiksen M, Vorkamp K, Thomsen M, Knudsen LE (2009) Human internal and external exposure to PBDEs-a review of levels and sources. Int J Hyg Environ Health 212(2):109-134. doi:10.1016/j.ijheh.2008.04.005

Fukuyo Y, Hunt CR, Horikoshi N (2010) Geldanamycin and its anticancer activities. Cancer Lett 290(1):24-35. doi:10.1016/j. canlet.2009.07.010

Furst P (2006) Dioxins, polychlorinated biphenyls and other organohalogen compounds in human milk. Levels, correlations, trends and exposure through breastfeeding. Mol Nutr Food Res 50(10):922-933. doi:10.1002/mnfr.200600008

Gascon M, Fort M, Martinez D et al (2012) Polybrominated diphenyl ethers (PBDEs) in breast milk and neuropsychological development in infants. Environ Health Perspect 120(12):1760-1765. doi:10.1289/ehp.1205266 
Giordano G, Costa LG (2012) Developmental neurotoxicity: some old and new issues. ISRN Toxicol 2012:12. doi: $10.5402 / 2012 / 814795$

Gojo I, Jiemjit A, Trepel JB et al (2007) Phase 1 and pharmacologic study of MS-275, a histone deacetylase inhibitor, in adults with refractory and relapsed acute leukemias. Blood 109(7):27812790. doi:10.1182/blood-2006-05-021873

Goldberg T, Berrios-Colon E (2013) Abiraterone (zytiga), a novel agent for the management of castration-resistant prostate cancer. Pharm Ther 38(1):23-26

Goshman LM (1985) Clinical toxicology of commercial products, 5th ed. By R. E. Gosselin, R. P. Smith, and H. C. Hodge. Williams and Wilkins, 428 East Preston Street, Baltimore, MD 21202. 1984. $1987+$ ix pp. $26 \times 17.5 \mathrm{~cm}$. ISBN 0-68303632-7. \$95.00. J Pharm Sci 74(10):1139. doi:10.1002/ jps.2600741037

Grandjean P, Herz KT (2011) Methylmercury and brain development: imprecision and underestimation of developmental neurotoxicity in humans. Mt Sinai J Med 78(1):107-118. doi:10.1002/ msj. 20228

Grandjean P, Herz KT (2015) Trace elements as paradigms of developmental neurotoxicants: Lead, methylmercury and arsenic. J Trace Elem Med Biol 31:130-134. doi:10.1016/j. jtemb.2014.07.023

Grandjean P, Landrigan PJ (2006) Developmental neurotoxicity of industrial chemicals. Lancet 368(9553):2167-2178. doi:10.1016/S0140-6736(06)69665-7

Greene HL, Graham EL, Werner JA et al (1983) Toxic and therapeutic effects of amiodarone in the treatment of cardiac arrhythmias. $\mathbf{J}$ Am Coll Cardiol 2(6):1114-1128

Gulden M, Seibert H (2003) In vitro-in vivo extrapolation: estimation of human serum concentrations of chemicals equivalent to cytotoxic concentrations in vitro. Toxicology 189(3):211-222

Harada M (1995) Minamata disease: methylmercury poisoning in Japan caused by environmental pollution. Crit Rev Toxicol 25(1):1-24. doi:10.3109/10408449509089885

Hartung T, Leist M (2008) Food for thought on the evolution of toxicology and the phasing out of animal testing. ALTEX 25(2):91-102

Henley DV, Korach KS (2010) Physiological effects and mechanisms of action of endocrine disrupting chemicals that alter estrogen signaling. Hormones (Athens) 9(3):191-205

http://www.epa.gov/epawaste/hazard/tsd/pcbs/pubs/effects.htm

http://www.fao.org/fileadmin/templates/agphome/documents/Pests_ Pesticides/JMPR/Report10/Cyproconazole.pdf

http://www.who.int/vaccine_safety/committee/topics/thiomersal/ statement_jul2006/en/

Hurley AM, Tadrous M, Miller ES (2010) Thimerosal-containing vaccines and autism: a review of recent epidemiologic studies. J Pediatr Pharmacol Ther 15(3):173-181

International Programme on Chemical Safety http://www.inchem.org/ documents/pims/pharm/pim441.htm

Itoh K, Tezuka H, Sakoda H et al (1989) Reproducible establishment of hemopoietic supportive stromal cell lines from murine bone marrow. Exp Hematol 17(2):145-153

Iversen P, Beck B, Chen Y, et al (2012) HTS assay validation. In: Sittampalam GS Coussens N, Nelson H, et al (eds) Assay Guidance Manual [Internet]. Eli Lilly \& Company and the National Center for Advancing Translational Sciences; 2004, Bethesda, MD

Jacobson JL, Jacobson SW (2001) Postnatal exposure to PCBs and childhood development. Lancet 358(9293):1568-1569. doi:10.1016/S0140-6736(01)06669-7

Kadereit S, Zimmer B, van Thriel C, Hengstler JG, Leist M (2012) Compound selection for in vitro modeling of developmental neurotoxicity. Front Biosci 17:2442-2460
Kern I, Xu R, Julien S et al (2013) Embryonic stem cell-based screen for small molecules: cluster analysis reveals four response patterns in developing neural cells. Curr Med Chem 20(5):710-723

Kim ES, Hirsh V, Mok T et al (2008) Gefitinib versus docetaxel in previously treated non-small-cell lung cancer (INTEREST): a randomised phase III trial. Lancet 372(9652):1809-1818. doi:10.1016/S0140-6736(08)61758-4

Klaric M, Winkler J, Vojnits K et al (2013) Current status of human pluripotent stem cell based in vitro toxicity tests. Front Biosci $5: 118-133$

Kreyberg S, Torvik A, Bjorneboe A, Wiik-Larsen W, Jacobsen D (1992) Trimethyltin poisoning: report of a case with postmortem examination. Clin Neuropathol 11(5):256-259

Krug AK, Balmer NV, Matt F, Schonenberger F, Merhof D, Leist M (2013a) Evaluation of a human neurite growth assay as specific screen for developmental neurotoxicants. Arch Toxicol 87(12):2215-2231. doi:10.1007/s00204-013-1072-y

Krug AK, Kolde R, Gaspar JA et al (2013b) Human embryonic stem cell-derived test systems for developmental neurotoxicity: a transcriptomics approach. Arch Toxicol 87(1):123-143. doi:10.1007/s00204-012-0967-3

Kuegler PB, Zimmer B, Waldmann T et al (2010) Markers of murine embryonic and neural stem cells, neurons and astrocytes: reference points for developmental neurotoxicity testing. ALTEX 27(1):17-42

Kummar S, Gutierrez M, Gardner ER et al (2007) Phase I trial of MS-275, a histone deacetylase inhibitor, administered weekly in refractory solid tumors and lymphoid malignancies. Clin Cancer Res 13(18 Pt 1):5411-5417. doi:10.1158/1078-0432. CCR-07-0791

Kummar S, Gutierrez ME, Gardner ER et al (2010) Phase I trial of 17-dimethylaminoethylamino-17-demethoxygeldanamycin (17-DMAG), a heat shock protein inhibitor, administered twice weekly in patients with advanced malignancies. Eur J Cancer 46(2):340-347. doi:10.1016/j.ejca.2009.10.026

Laske C, Stellos K, Stransky E, Leyhe T, Gawaz M (2009) Decreased plasma levels of granulocyte-colony stimulating factor (G-CSF) in patients with early Alzheimer's disease. J Alzheimers Dis 17(1):115-123. doi:10.3233/JAD-2009-1017

Lawless MW, Norris S, O’Byrne KJ, Gray SG (2009) Targeting histone deacetylases for the treatment of disease. J Cell Mol Med 13(5):826-852. doi:10.1111/j.1582-4934.2008.00571.x

Leist M, Hartung T (2013) Inflammatory findings on species extrapolations: humans are definitely no 70-kg mice. Arch Toxicol 87(4):563-567. doi:10.1007/s00204-013-1038-0

Leist M, Hartung T, Nicotera P (2008) The dawning of a new age of toxicology. ALTEX 25(2):103-114

Leist M, Hasiwa N, Rovida C et al (2014) Consensus report on the future of animal-free systemic toxicity testing. ALTEX 31(3):341-356. doi:10.14573/altex.1406091

Leist M, Ringwald A, Kolde R et al (2013) Test systems of developmental toxicity: state-of-the art and future perspectives. Arch Toxicol 87(12):2037-2042. doi:10.1007/s00204-013-1154-x

Linden R, Ziulkoski AL, Wingert M, Tonello P, Souto AA (2007) Simultaneous determination of omeprazole, hydroxyomeprazole and omeprazole sulphone in human plasma by isocratic HPLC-DAD: application to the phenotyping of CYP2C19 and CYP3A4 in brazilian volunteers. J Braz Chem Soc 18:733-740

Lindup WEI (1987) Plasma protein binding of drugs: some basic and clinical aspects. In: Bridges JW, Chasseaud LF, Gibson GG (eds) Progress in drug metabolism, vol 10. Taylor and Francis, London, pp 141-185

Lohren H, Blagojevic L, Fitkau R et al (2015) Toxicity of organic and inorganic mercury species in differentiated human neurons and human astrocytes. J Trace Elem Med Biol 32:200-208. doi:10.1016/j.jtemb.2015.06.008 
Lu E, Wang BW, Alwan S et al (2014) A review of safety-related pregnancy data surrounding the oral disease-modifying drugs for multiple sclerosis. CNS Drugs 28(2):89-94. doi:10.1007/ s40263-013-0131-5

MacDonald E, Dadds MR, Brennan JL, Williams K, Levy F, Cauchi AJ (2011) A review of safety, side-effects and subjective reactions to intranasal oxytocin in human research. Psychoneuroendocrinology 36(8):1114-1126. doi:10.1016/j. psyneuen.2011.02.015

Maruyama R, Nishiwaki Y, Tamura T et al (2008) Phase III study, V-15-32, of gefitinib versus docetaxel in previously treated Japanese patients with non-small-cell lung cancer. J Clin Oncol 26(26):4244-4252. doi:10.1200/JCO.2007.15.0185

Messer A (2010) Mini-review: polybrominated diphenyl ether (PBDE) flame retardants as potential autism risk factors. Physiol Behav 100(3):245-249. doi:10.1016/j.physbeh.2010.01.011

Mlejnek P, Dolezel P (2014) N-acetylcysteine prevents the geldanamycin cytotoxicity by forming geldanamycin- $\mathrm{N}$-acetylcysteine adduct. Chem Biol Interact 220:248-254. doi:10.1016/j. cbi.2014.06.025

Morris E, Green D, Graudins A (2009) Neuroleptic malignant syndrome developing after acute overdose with olanzapine and chlorpromazine. J Med Toxicol 5(1):27-31

Orr CF, Ahlskog JE (2009) Frequency, characteristics, and risk factors for amiodarone neurotoxicity. Arch Neurol 66(7):865-869. doi:10.1001/archneurol.2009.96

Ozkan H, Cetinkaya M, Koksal N, Yapici S (2011) Severe fetal valproate syndrome: combination of complex cardiac defect, multicystic dysplastic kidney, and trigonocephaly. J Matern Fetal Neonatal Med 24(3):521-524. doi:10.3109/14767058.2010.50 1120

Patejdl R, Markmann S, Benecke R, Wittstock M (2013) Severe acute motor neuropathy after treatment with triple tyrosine kinase inhibitor BIBF 1120 (Nintedanib). Clin Neurol Neurosurg 115(9):1851-1852. doi:10.1016/j.clineuro.2013.01.011

Patel S (2013) Long-term efficacy of imatinib for treatment of metastatic GIST. Cancer Chemother Pharmacol 72(2):277-286. doi:10.1007/s00280-013-2135-8

Patterson DG Jr, Needham LL, Pirkle JL et al (1988) Correlation between serum and adipose tissue levels of 2,3,7,8-tetrachlorodibenzo-p-dioxin in 50 persons from Missouri. Arch Environ Contam Toxicol 17(2):139-143

Pellacani C, Tagliaferri S, Caglieri A et al (2014) Synergistic interactions between PBDEs and PCBs in human neuroblastoma cells. Environ Toxicol 29(4):418-427. doi:10.1002/tox.21768

Perrin D, Martin T, Cambet Y, Fremaux C, Scheer A (2006) Overcoming the hurdle of fluorescent compounds in kinase screening: a case study. Assay Drug Dev Technol 4(2):185-196. doi:10.1089/adt.2006.4.185

Pichichero ME, Gentile A, Giglio N et al (2008) Mercury levels in newborns and infants after receipt of thimerosal-containing vaccines. Pediatrics 121(2):e208-e214. doi:10.1542/ peds.2006-3363

Pili R, Salumbides B, Zhao M et al (2012) Phase I study of the histone deacetylase inhibitor entinostat in combination with 13-cis retinoic acid in patients with solid tumours. Br J Cancer 106(1):77-84. doi:10.1038/bjc.2011.527

Pistollato F, Bremer-Hoffmann S, Healy L, Young L, Stacey G (2012) Standardization of pluripotent stem cell cultures for toxicity testing. Expert Opin Drug Metab Toxicol 8(2):239-257. doi:10. $1517 / 17425255.2012 .639763$

Plosker GL (2011) Interferon-beta-1b: a review of its use in multiple sclerosis. CNS Drugs 25(1):67-88. doi:10.2165/11206430-000000000-00000

Poole RM (2014) Belinostat: first global approval. Drugs 74(13):1543-1554. doi:10.1007/s40265-014-0275-8
Preynat-Seauve O, Suter DM, Tirefort D et al (2009) Development of human nervous tissue upon differentiation of embryonic stem cells in three-dimensional culture. Stem Cells 27(3):509-520. doi:10.1634/stemcells.2008-0600

Rasmussen TA, Tolstrup M, Moller HJ et al (2015) Activation of latent human immunodeficiency virus by the histone deacetylase inhibitor panobinostat: a pilot study to assess effects on the central nervous system. Open Forum Infect Dis 2(1):ofv037. doi:10.1093/ofid/ofv037

Reboli AC, Mandler HD (1992) Encephalopathy and psychoses associated with sulfadiazine in two patients with AIDS and CNS toxoplasmosis. Clin Infect Dis 15(3):556-557

Reeves R, Thiruchelvam M, Richfield EK, Cory-Slechta DA (2004) The effect of developmental exposure to the fungicide triadimefon on behavioral sensitization to triadimefon during adulthood. Toxicol Appl Pharmacol 200(1):54-63. doi:10.1016/j. taap.2004.03.020

Rempel E, Hoelting L, Waldmann T et al (2015) A transcriptomebased classifier to identify developmental toxicants by stem cell testing: design, validation and optimization for histone deacetylase inhibitors. Arch Toxicol 89(9):1599-1618. doi:10.1007/ s00204-015-1573-y

Richardson PG, Schlossman RL, Alsina M et al (2013) PANORAMA 2: panobinostat in combination with bortezomib and dexamethasone in patients with relapsed and bortezomibrefractory myeloma. Blood 122(14):2331-2337. doi:10.1182/ blood-2013-01-481325

Rinne ML, Lee EQ, Wen PY (2012) Central nervous system complications of cancer therapy. J Support Oncol 10(4):133-141. doi:10.1016/j.suponc.2011.11.002

Robinson JF, Theunissen PT, van Dartel DA, Pennings JL, Faustman EM, Piersma AH (2011) Comparison of MeHg-induced toxicogenomic responses across in vivo and in vitro models used in developmental toxicology. Reprod Toxicol 32(2):180-188. doi:10.1016/j.reprotox.2011.05.011

Rovida C, Longo F, Rabbit RR (2011) How are reproductive toxicity and developmental toxicity addressed in REACH dossiers? ALTEX 28(4):273-294

Roysommuti S, Carroll SL, Wyss JM (2003) Neuregulin-1beta modulates in vivo entorhinal-hippocampal synaptic transmission in adult rats. Neuroscience 121(3):779-785

Ruiz R, Raez LE, Rolfo C (2015) Entinostat (SNDX-275) for the treatment of non-small cell lung cancer. Expert Opin Investig Drugs 24(8):1101-1109. doi:10.1517/13543784.2015.1056779

Russo PA, Wiese MD, Smith MD, Ahern MJ, Barbara JA, Shanahan EM (2013) Leflunomide for inflammatory arthritis in endstage renal disease on peritoneal dialysis: a pharmacokinetic and pharmacogenetic study. Ann Pharmacother 47(3):e15. doi:10.1345/aph.1R542

Schneider A, Kuhn HG, Schabitz WR (2005) A role for G-CSF (granulocyte-colony stimulating factor) in the central nervous system. Cell Cycle 4(12):1753-1757

Silva-Pereira LC, Cardoso PC, Leite DS et al (2005) Cytotoxicity and genotoxicity of low doses of mercury chloride and methylmercury chloride on human lymphocytes in vitro. Braz J Med Biol Res 38(6):901-907

Smirnova L, Hogberg HT, Leist M, Hartung T (2014) Developmental neurotoxicity: challenges in the 21 st century and in vitro opportunities. ALTEX 31(2):129-156. doi:10.14573/altex.1403271

Smith J, Whitehall J (2009) Sodium valproate and the fetus: a case study and review of the literature. Neonatal Netw 28(6):363367. doi:10.1891/0730-0832.28.6.363

Stefanska B, MacEwan DJ (2015) Epigenetics and pharmacology. Br J Pharmacol 172(11):2701-2704. doi:10.1111/bph.13136

Stiegler NV, Krug AK, Matt F, Leist M (2011) Assessment of chemical-induced impairment of human neurite outgrowth by 
multiparametric live cell imaging in high-density cultures. Toxicol Sci 121(1):73-87. doi:10.1093/toxsci/kfr034

Subiros N, Del Barco DG, Coro-Antich RM (2012) Erythropoietin: still on the neuroprotection road. Ther Adv Neurol Disord 5(3):161-173. doi:10.1177/1756285611434926

Sun HH, Saheb-Al-Zamani M, Yan Y, Hunter DA, Mackinnon SE, Johnson PJ (2012) Geldanamycin accelerated peripheral nerve regeneration in comparison to FK-506 in vivo. Neuroscience 223:114-123. doi:10.1016/j.neuroscience.2012.07.026

Suñol C, Rodríguez-Farré E (2012) In Vitro models for methylmercury neurotoxicity: effects on glutamatergic cerebellar granule neurons. In: Ceccatelli S, Aschner M (eds) Methylmercury and neurotoxicity. Current topics in neurotoxicity, vol 2. Springer, pp 259-270

Supko JG, Hickman RL, Grever MR, Malspeis L (1995) Preclinical pharmacologic evaluation of geldanamycin as an antitumor agent. Cancer Chemother Pharmacol 36(4):305-315. doi:10.1007/BF00689048

Suter DM, Cartier L, Bettiol E et al (2006) Rapid generation of stable transgenic embryonic stem cell lines using modular lentivectors. Stem Cells 24(3):615-623. doi:10.1634/stemcells.2005-0226

Suter DM, Preynat-Seauve O, Tirefort D, Feki A, Krause KH (2009) Phenazopyridine induces and synchronizes neuronal differentiation of embryonic stem cells. J Cell Mol Med 13(9B):35173527. doi:10.1111/j.1582-4934.2009.00660.x

Sweatman TW, Renwick AG, Burgess CD (1981) The pharmacokinetics of saccharin in man. Xenobiotica 11(8):531-540

Theunissen PT, Pennings JL, Robinson JF, Claessen SM, Kleinjans JC, Piersma AH (2011) Time-response evaluation by transcriptomics of methylmercury effects on neural differentiation of murine embryonic stem cells. Toxicol Sci 122(2):437-447. doi:10.1093/toxsci/kfr134

Thompson WW, Price C, Goodson B et al (2007) Early thimerosal exposure and neuropsychological outcomes at 7 to 10 years. N Engl J Med 357(13):1281-1292. doi:10.1056/NEJMoa071434

Tsuji R, Crofton KM (2012) Developmental neurotoxicity guideline study: issues with methodology, evaluation and regulation. Congenit Anom 52(3):122-128. doi:10.1111/j.1741-4520.2012.00374.x

US FDA (2011) Pharmacology review: abiraterone acetate (ZYTIGA). Center for drug evaluation and research, submission number 202379Orig1s000. http://www.accessdata.fda.gov/ drugsatfda_docs/nda/2011/202379Orig1s000PharmR.pdf

US FDA (2012) Center for drug evaluation and research, Pharmacology Review Teriflunomide, submission number 202992Orig1s000. http://www.accessdata.fda.gov/drugsatfda_ docs/nda/2012/202992Orig1s000PharmR.pdf

Vahidnia A, van der Voet GB, de Wolff FA (2007) Arsenic neurotoxicity: a review. Hum Exp Toxicol 26(10):823-832. doi: $10.1177 / 0960327107084539$

van Thriel C, Westerink RH, Beste C, Bale AS, Lein PJ, Leist M (2012) Translating neurobehavioural endpoints of developmental neurotoxicity tests into in vitro assays and readouts. Neurotoxicology 33(4):911-924. doi:10.1016/j.neuro.2011.10.002

van Vliet E, Daneshian M, Beilmann M et al (2014) Current approaches and future role of high content imaging in safety sciences and drug discovery. ALTEX 31(4):479-493. doi:10.14573/altex.1405271 van Vliet E, Morath S, Eskes C et al (2008) A novel in vitro metabolomics approach for neurotoxicity testing, proof of principle for methyl mercury chloride and caffeine. Neurotoxicology 29(1):1-12. doi:10.1016/j.neuro.2007.09.007

Varela MA, Roberts TC, Wood MJ (2013) Epigenetics and ncRNAs in brain function and disease: mechanisms and prospects for therapy. Neurotherapeutics 10(4):621-631. doi:10.1007/ s13311-013-0212-7

Verrotti A, Scaparrotta A, Cofini M, Chiarelli F, Tiboni GM (2014) Developmental neurotoxicity and anticonvulsant drugs: a possible link. Reprod Toxicol 48:72-80. doi:10.1016/j. reprotox.2014.04.005

Verwei M, van Burgsteden JA, Krul CA, van de Sandt JJ, Freidig AP (2006) Prediction of in vivo embryotoxic effect levels with a combination of in vitro studies and PBPK modelling. Toxicol Lett 165(1):79-87. doi:10.1016/j.toxlet.2006.01.017

Waldmann T, Rempel E, Balmer NV et al (2014) Design principles of concentration-dependent transcriptome deviations in drug-exposed differentiating stem cells. Chem Res Toxicol 27(3):408-420. doi:10.1021/tx400402j

Wang C, Luan Z, Yang Y, Wang Z, Cui Y, Gu G (2011) Valproic acid induces apoptosis in differentiating hippocampal neurons by the release of tumor necrosis factor-alpha from activated astrocytes. Neurosci Lett 497(2):122-127. doi:10.1016/j.neulet.2011.04.044

Wei DG, Chiang V, Fyne E et al (2014) Histone deacetylase inhibitor romidepsin induces HIV expression in CD4 T cells from patients on suppressive antiretroviral therapy at concentrations achieved by clinical dosing. PLoS Pathog 10(4):e1004071. doi:10.1371/journal.ppat.1004071

Welsch F (2005) The mechanism of ethylene glycol ether reproductive and developmental toxicity and evidence for adverse effects in humans. Toxicol Lett 156(1):13-28. doi:10.1016/j. toxlet.2003.08.010

Westermark T, Odsjö T, Johnels-Ambio AG (1975) Mercury content of bird feathers before and after Swedish ban on alkyl mercury in agriculture. Ambio 4:87-92

Willis MS, Lugo AM (2009) Amiodarone-induced neurotoxicity. Am J Health Syst Pharm 66(6):567-569. doi:10.2146/ajhp080196

$\mathrm{Wu}$ WC, Wu MH, Chang YC et al (2010) Geldanamycin and its analog induce cytotoxicity in cultured human retinal pigment epithelial cells. Exp Eye Res 91(2):211-219. doi:10.1016/j. exer.2010.05.005

Xu R, Feyeux M, Julien S et al (2014) Screening of bioactive peptides using an embryonic stem cell-based neurodifferentiation assay. AAPS J 16(3):400-412. doi:10.1208/s12248-014-9578-7

Zimmer B, Kuegler PB, Baudis B et al (2011) Coordinated waves of gene expression during neuronal differentiation of embryonic stem cells as basis for novel approaches to developmental neurotoxicity testing. Cell Death Differ 18(3):383-395. doi: $10.1038 /$ cdd.2010.109

Zimmer B, Lee G, Balmer NV et al (2012) Evaluation of developmental toxicants and signaling pathways in a functional test based on the migration of human neural crest cells. Environ Health Perspect 120(8):1116-1122. doi:10.1289/ehp.1104489

Zimmer B, Pallocca G, Dreser N et al (2014) Profiling of drugs and environmental chemicals for functional impairment of neural crest migration in a novel stem cell-based test battery. Arch Toxicol 88(5):1109-1126. doi:10.1007/s00204-014-1231-9 